\title{
Advanced Materials for Membrane-Based Gas Separation
}

\author{
A. F. Ismail ${ }^{1 *}$, T. D. Kusworo ${ }^{2}$, A. Mustafa ${ }^{3}$ \& H. Hasbullah ${ }^{4}$ \\ 1,2,3\&4 Membrane Research Unit, Faculty of Chemical and Natural Resources Engineering \\ Universiti Teknologi Malaysia, 81310 UTM, Skudai, Johor Bahru, Malaysia \\ ${ }^{2}$ Department of Chemical Engineering, University of Diponegoro \\ Jl. Prof. Sudharto, Tembalang, Indonesia
}

\begin{abstract}
The development of advanced materials for membrane gas separation has received much attention in the recent years. There are many important aspects involved in the development of new and advanced membrane materials including the type of material, transport mechanism, the relationship between membrane structure and performance and membrane preparation techniques. There are numerous materials being widely investigated as suitable candidates using advanced materials for membrane gas separation. Therefore, this paper discusses the progress in the development of an advanced membrane material and methods to prepare membranes for gas separation. The recent development and future direction in membrane material research are also presented.
\end{abstract}

Keywords : Gas separation membrane, advanced materials

\subsection{INTRODUCTION}

Membrane separation technology is currently one of the most innovative and rapidly growing fields across science and engineering. The preparation of asymmetric cellulose acetate membranes in the early $1960 \mathrm{~s}$ by Loeb and Sourirajan is widely known as a pivotal moment for membrane technology. They developed a new method that significantly increased the permeation flux of polymeric membranes without any significant changes in selectivity, which made it possible to use membranes in largescale application. In addition, basic properties of membrane operations make them ideal for industrial application; they are generally thermal and do not involve phase changes or chemical additives, the membrane concept and operation are simple in modules and easy to be scaled-up. Besides that, the energy consumption is low with a potential for more rational utilization of raw materials as well as recovery and reuse of by-products. As compared to the conventional separation method, membrane technologies respond efficiently to the requirement of so-called "process intensification". This is because membranes permit drastic improvements in manufacturing and processing, substantially decreasing the equipment-size/production-capacity ratio, energy consumption, and/or waste production. Thus, this will result in cheaper sustainable technical solutions.

*Correspondence: A. F. Ismail (Tel: +60-7-5535592, Fax: +60-7-5581463, Email: afauzi@utm.my) 
Gas separation is another application of the rapidly developing membrane technology. The production of a gas at a specific purity from a multi-component gas mixture can be achieved using the conventional gas separation techniques such as adsorption, absorption and cryogenic distillation. In gas separation by membranes, the gases are separated based on the differences in their solubility and diffusivity in the membrane. The important factors affecting the application of membrane in gas separation are feed composition, membrane materials, membrane configuration, plant capacity and operating costs. The membrane separation processes provide several advantages over the conventional separation techniques. First, the membrane process is a viable energy-saving alternative for $\mathrm{CO}_{2}$ separation, since it does not require any phase transformation. Secondly, the necessary process equipment is very simple with no moving parts, compact and relatively easy to operate and control.

Membrane gas separation techniques began with the work of J. K. Mitchell in 1831 who measured the escaping rates of ten different gases through natural rubber balloons. In the 1830's, Ficks studied gas transport across nitrocellulose membranes and formulated his Law of Diffusion. The foundation for gas separation was laid by Thomas Graham in 1829 , who carried out the experiment on the transport of gases and vapours in polymeric membranes. In 1866, Thomas Graham published the concepts of gas permeation in terms of a solution-diffusion mechanism. Benchold (1907) reported a preparation technique of graded pore-size structure for nitrocellulose membrane. Twenty years later, other polymers like cellulose acetate were experimented in producing microfiltration membrane. Such membranes found their first significant applications in the filtration of drinking water. In the end of 1960 , the element of modern membrane science had been developed and sufficient knowledge was available on the relationships between structure and function in gas separation membrane. However, the technology to fabricate the modules economically was lacking. During the 1970's, Dupont and Dow Company began to develop large-scale gas separation modules. There were several breakthroughs in the gas separation field during this time, including the introduction of the composite membrane. This membrane has a thin selective layer bonded to a porous supporting layer usually of a different polymer. In early 1980 , Monsanto had commercially produced gas separation membranes modules called PRISM. These PRISM modules contained polysulfone hollow fibers for the recovery of hydrogen from ammonia plant. This was the first large industrial application of gas separation membranes. Since then, membrane based gas separation was used in more than 100 installation worldwide. Cynara and the Separex Company used membranes for the separation of carbon dioxide. The progress in membrane science and technology accelerated during the 1980s due to the development and refinement of synthetic polymeric membranes. Membrane gas separation had emerged as a commercial process on a large-scale during 1980s. During this period, significant progress was made virtually in every aspect of membranology, including improvements in membrane formation processes, chemical and physical structures, configuration and applications. A milestone in the development of membrane gas separation technology is given in Table 1.

Currently, studies in academic and industrial laboratories are concerned in reducing the cost of membrane processes for gas separation. Therefore, many investigations are devoted to develop membranes that exhibit both high selectivity and permeability than available membranes. In this paper, the principle of membrane processes, gas separation mechanisms and type of membrane materials are reviewed. Furthermore, the development and future directions of new or improved materials of membranes for membrane-based gas separation are discussed.

\subsection{FUNDAMENTALS OF GAS TRANSPORT THROUGH MEMBRANE}

The transport phenomena through polymer membrane can be divided into five successive stages and are presented in Figure 1 [1]: 
(i) Diffusion through the limit layer of the side corresponding to the higher partial pressure $\left(p_{1}\right) ;$

(ii) Absorption of the gas (by chemical affinity or by solubility) by the polymer;

(iii) Diffusion of the gas inside the membrane polymer;

(iv) Desorption of the gas at the side of lower partial pressure $\left(p_{2}\right)$;

(v) Diffusion through the limit layer of the downstream side.

From Figure 1, the resistance indicated by step 1 and 5 are negligible relative to others and the formation of a limit layer of gas on each side of the membrane is not observed. The transport of gas molecules through a homogeneous polymer matrix can be described as the following process: condensation and solution of the penetrant at one surface of the membrane, followed by diffusion, in

Table 1 Milestones in the development of membrane gas separations

\begin{tabular}{lll}
\hline Year & \multicolumn{1}{c}{ Thesearcher } \\
1850 & Van Amerongen & Membrane system \\
1950 & Loeb and Sourirajan & $\begin{array}{l}\text { Spiral wound and hollow fiber modules for reverse } \\
\text { osmosis }\end{array}$ \\
$1960-1970$ & Prism membrane for $\mathrm{H}_{2}$ separation \\
1980 & Permea & $\mathrm{N}_{2} /$ air separation system \\
1982 & Generon & $\mathrm{O}_{2} / \mathrm{N}_{2} ; \mathrm{H}_{2} / \mathrm{N}_{2} ; \mathrm{H}_{2} / \mathrm{CH}_{4}$ separation system \\
1987 & Ube, Medal, Generon & Vapour separation \\
1988 & MTR, GKSS Nitto Denko & Cellulose acetate for $\mathrm{CO}_{2} / \mathrm{CH}_{4}$ separation \\
1990 & Separex, Cynara, GMS & Polyimide membrane for $\mathrm{CO}_{2} / \mathrm{CH}_{4}$ separation \\
1994 & Medal & Propylene/ $\mathrm{N}_{2}$ separation \\
1996 & Permea & Many process separation \\
$2000-$ & Permea, Air liquid Generon &
\end{tabular}

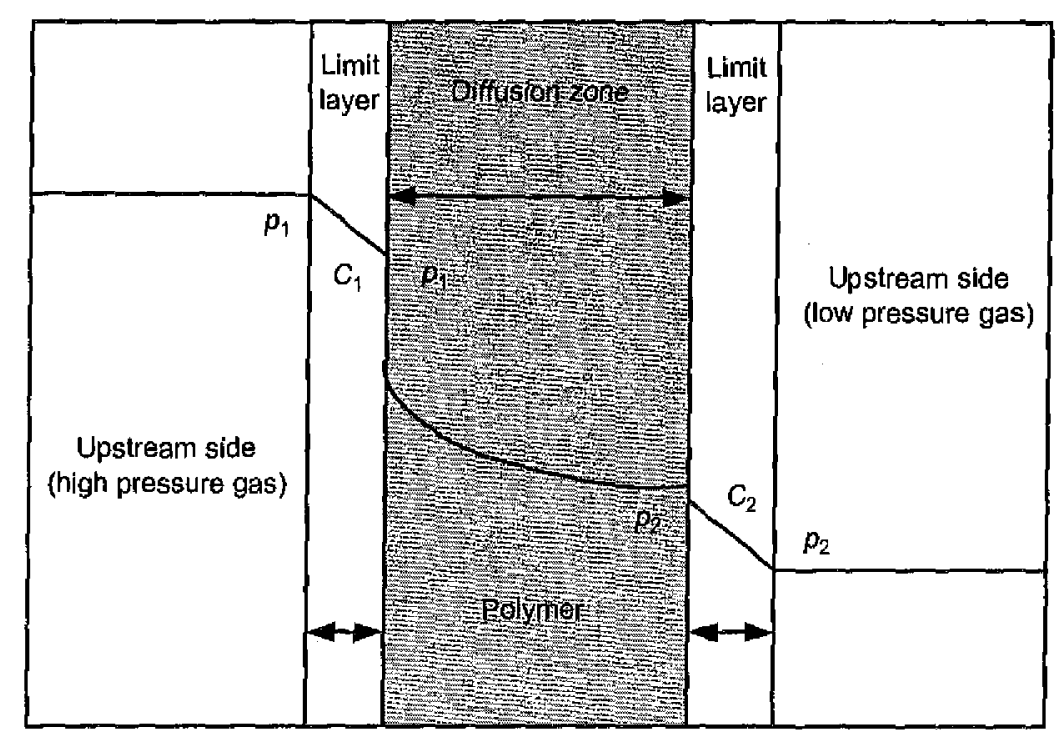

Figure 1 Schematic representation of the different resistances encountered by a molecule diffusing through a polymer membrane at a fixed temperature 
a form of a liquid, through it under the influence of a concentration gradient (chemical potential) and finally, evaporation at the other surface to the gaseous state [2].

Diffusion is the process by which small molecules (organic liquids, vapours, gases, etc.) are transferred in the system due to random molecular motions. It is a kinetic term that reflects the penetrant mobility in the polymer phase. Consider a polymer membrane of thickness $l$, and surface $A$ is submitted to a fluid and $Q$, the total amount of penetrant has passed through this membrane at time $t$. The diffusive flux of a penetrant molecule $(J)$ is given by:

$$
J=Q / A t
$$

The Fick's first law establishes a linear relation between the flux of the substance diffusing through a membrane and the concentration gradient between both sides of the membrane:

$$
J=-D(\partial c / \partial x)
$$

where $D$ is the diffusion coefficient $\left(\mathrm{cm}^{2} / \mathrm{s}\right)$. This first law is applicable at steady state when the concentration does not vary with time and the flux is constant. On the other hand, Fick's second law describes the non-steady state for transport process, which is given by the rate of change of the penetrant concentration $(\partial c / \partial x)$ at a plane within the membrane, i.e.

$$
\left(\frac{\partial c}{\partial t}\right)=D\left(\frac{\partial c^{2}}{\partial x^{2}}\right)
$$

This is an ideal case in which the membrane is isotropic and the diffusion coefficient is independent of distance, time and concentration. Depending on the boundary conditions, many solutions are available from Equation (3). A strong polymer penetrant interaction occurs with many organic penetrant molecules. Hence $D$ is dependent on concentration. Therefore, Equation (3) becomes,

$$
\left(\frac{\partial c}{\partial t}\right)=D \frac{\partial D(c)(\partial c / \partial x)}{\partial x}
$$

Analytically, this cannot be solved easily and hence another form of Equation (4) is commonly used as in Equation (5).

$$
\left(\frac{\partial c}{\partial t}\right)=D(c) \frac{\partial c^{2}}{\partial x^{2}}+\frac{\partial D(c)}{\partial c}\left(\frac{\partial c}{\partial x}\right)
$$

Gẹnerally, experiments are conducted over a relatively small interval of $c$ and the term $(\partial D(c) / \partial c)$ is negligible compared to $D(c)$. Then, we get a mean or integral diffusion coefficient $D$ over a concentration range of $c_{1}$ to $c_{2}$, as given by:

$$
D=\int_{c_{1}}^{c_{2}} D(c) d c / c_{1}-c_{2}
$$

where $c_{1}$ and $c_{2}$ are the concentrations of the penetrant at the low and high concentration faces of the film, respectively. At steady state condition, diffusion flow is constant and the diffusion coefficient is independent of concentration. In this case, Equation (2) may be integrated to give:

$$
J=\frac{D\left(c_{1}-c_{2}\right)}{h}
$$


where $h$ is the membrane thickness. The penetrant distribution between the penetrant and the polymer phase is described by the Nernst distribution law as,

$$
c=K C
$$

where $c$ is the sorbed concentration, $C$ is the ambient penetrant concentration in contact with the polymer surface and $K$ depends on temperature and $c$. In the case of transport of gases and vapours, pressure $p$ is used instead of surface concentration. According to Henry's law,

$$
c=S p
$$

where $S$ is the solubility coefficient. The combination of Equations (6) and (8) gives the well known permeation equation,

$$
J=\frac{D S\left(p_{1}-p_{2}\right)}{h}
$$

where $p_{1}$ and $p_{2}$ are the ambient pressures on the two sides of a film with thickness $h$. The product $D S$ is called the permeability coefficient $P$, so that

$$
P=D S
$$

In terms of permeability, the flux Equation (10) can be written as:

$$
J=\frac{P\left(p_{1}-p_{2}\right)}{h}
$$

\subsection{Mechanisms of Gas Transport}

The mass transfer of gas through a porous plug involves several processes, depending on the nature of the pore structure and the solid. There are four different mechanisms for separation of a gas mixture through a porous membrane: Knudsen diffusion, solution-diffusion, surface diffusion/selective adsorption and molecular sieving. Knudsen diffusion relies on the different molecular weights of the gases. The gas separation with glassy polymer membrane is determined by molecular sieve effect. Apart from the lack of suitable mechanical properties and difficulties in creating large membrane surface, fouling caused by condensable impurities in the gas stream turns out to be a significant problem.

In 1866 , Graham postulated the model concepts for the mechanism of gas permeation that are still applicable today. He observed that the rates of gases flowed through a membrane did not correlate with the well known gas diffusion constants. Therefore, he concluded that the transport did not occur through pores (defects in the polymer film), at least not to a significant degree but indeed through the membrane material itself. The membranes that are currently commercially available and the majority of the membranes studied in a laboratory operate according to the solution-diffusion mechanism. According to the solution-diffusion mechanism, the passage of a gas through a non porous polymer film occurs in three stages. Initially, the gas must be dissolved in the membrane material, then the gas molecules must diffuse through the polymer and finally, the gas must be released. The rate of determining the parameter is known as the permeability coefficient. Stern et al. [3] reported that in order to understand the gas transport through polymer membranes, it is necessary to know at least two of the three parameters: permeability, diffusivity and solubility.

There are several factors affecting the gas transport membrane such as nature of the polymer, effect of plasticizers, nature of penetrant and filler. The transport behavior for a given penetrant 
varies from one polymer to another. Transport properties depend on the free volume within the polymer and on the segmental mobility of the polymer chains. The segmental mobility of the polymer chains is affected by the extent of unsaturation, degree of crosslinking, degree of crystallinity and nature of substituents. The glass transition temperature of polymers has a profound influence on transport properties. Polymers with low glass transition temperatures possess greater segmental mobility and have higher diffusivity.

\subsection{Gas Separation Membranes}

Membrane processes for gaseous mixture separation today are technically well developed and can be opted to substitute the traditional techniques. Moreover, membrane technology is widely applied at the industrial level. The separation of air components, natural gas dehumidification, as well as separation and recovery of $\mathrm{CO}_{2}$ from biogas and $\mathrm{H}_{2}$ from industrial gases are some examples of membrane applications in the industry. The gas separation business valued in 1996 was $\$ 85$ million in the U.S., with a growth of about $8 \%$ per year [4]. The flat sheet, spiral wound or hollow fibers that are made from asymmetric polymeric membranes are usually used for gas mixture separations. These modules are made and commercialized by several companies worldwide. Although the kind of module used is declared, the type of polymer is still protected as industrial propriety. Several hundreds new polymer materials have been reported in the past few years, and have substantially higher permeabilities and selectivities than those listed in Table 2. However, the development of membrane material is determined by costs, required product quality, and the availability of the material. Therefore, there are many attempts to invent new materials to overcome these constraints.

Table 2 Principal gas separation material and membrane systems

\begin{tabular}{llll}
\hline Company & Gas separation & $\begin{array}{l}\text { Principal membrane } \\
\text { material used }\end{array}$ & Module type \\
\hline Permea (Air product) & $\mathrm{N}_{2}$ /air, $\mathrm{H}_{2}$ separation, $\mathrm{CO}_{2} / \mathrm{CH}_{4}$ & $\begin{array}{l}\text { Polysulfone } \\
\text { Polyamide }\end{array}$ & Hollow fiber \\
Medal (Air liquid) & $\mathrm{N}_{2}$ /air & Polyamide & Hollow fiber \\
IMS & $\mathrm{H}_{2}$ separation & Tetrabromo polycarbonate & Hollow fiber \\
Generon (MG) & $\mathrm{H}_{2}$ separation & Cellulose acetate & Spiral wound \\
GMS (Kvaerner) & $\mathrm{Natural} \mathrm{gas} \mathrm{separation}_{\text {Separex (UOP) }}^{\mathrm{CO}_{2} / \mathrm{CH}_{4}}$ & Cellulose acetate & Spiral wound \\
Cynara & $\mathrm{CO}_{2} / \mathrm{CH}_{4}$ & Cellulose acetate & Hollow fiber \\
Aquilo & Vapour separation & Polyphenylene oxide & Hollow fiber \\
Parker-Hannifin & Vapour separation & Polyamide & Hollow fiber \\
MTR & Vapour separation & Silicone rubber & Spiral wound \\
\hline
\end{tabular}

The separation of air components or oxygen enrichment has advanced substantially during the past 10 years. The oxygen produced by membranes separation has been used in various fields, including chemical and related industries, medical and food packaging. Industrial nitrogen is used in the chemical industry to protect fuels and oxygen-sensitive materials. Membranes today dominate the fraction of nitrogen market for applications less than 50 tons/day and relatively low purity [4]. Oxygen is the third largest commodity chemical in the U.S. with annual sales in excess of $\$ 2$ billion. Although nitrogen membrane separation has been a great success, oxygen separation using membranes is still under developed. The major reason for this is that most of the oxygen industrial applications require 
purity higher than $90 \%$, which can be easily achieved by adsorption or cryogenic technologies. Today's limited applications of membrane-based oxygen generation systems operate either under feed compressed or vacuum mode permeate. However, permeability and selectivity are only two of the criteria that must be met to produce a useful membrane; others include the ability to form stable, thin, low-cost membranes and can be packaged into high-surface-area modules.

To obtain high permeation rate, the selective layer of gas separation membranes must be extremely thin. Typical membranes have an effective thickness of less than $0.1 \mu \mathrm{m}$. Many of these extremely thin membranes were made by various polymer phase separation process invented by Loeb and Sourirajan in the 1960s. These membranes consist of a thin, dense, nonporous skin layer that performs the separation, supported on a finely microporous substrate made from the same material that provides mechanical strength. Membranes can be formed as flat sheets or as fine capillaries (hollow fibers) of $50-500 \mu \mathrm{m}$ in diameter. Figure 2 shows the structure of this type of membrane. The method used to prepare anisotropic phase separation membranes limits the number of materials that can be formed into high-performance membranes. For this reason, membranes are increasingly formed as composite structures of the type shown in Figure 2(b). Composite membranes also contain less than $1 \mathrm{~g}$ of the selective polymer per square meter of the membrane, whereas anisotropic Loeb-Sourirajan membranes use $40-60 \mathrm{~g}$ of the selective polymer per square meter of membrane.

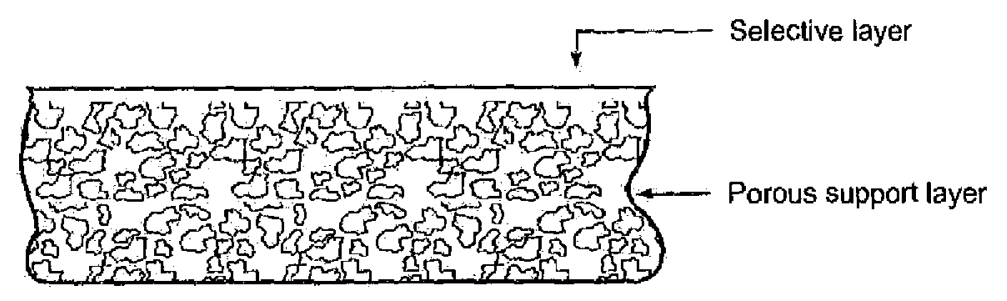

(a) Flat sheet and hollow fiber Loeb-Sourirajan anisotropic phase separation membrane

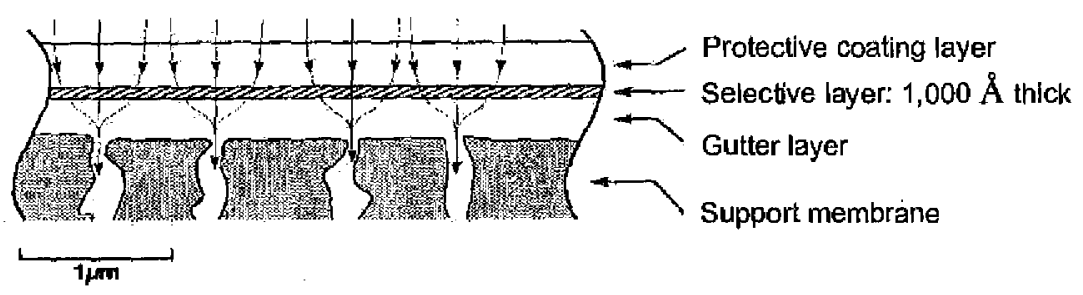

(b) Multilayer composite membrane

Figure 2 Gas separation membranes made by the Loeb-Sourirajan phase separation process or as composite membranes by a solution-coating procedure [5]

\subsection{TYPE OF MEMBRANE MATERIALS}

The diversity of membrane-based separation systems makes them difficult to be categorized clearly. The general types of membrane materials used today include inorganic and polymeric as well as ceramic and metal films with symmetric or asymmetric structure. 


\subsection{Inorganic Membrane}

Inorganic membranes can be classified into two categories based on structure: porous and dense. In porous inorganic membrane, a porous thin top layer is supported on a porous metal or ceramic, which provides mechanical strength but offers minimum mass transfer. Alumina, carbon, glass, silica, titania, zeolite and zirconia membranes are mainly used as porous inorganic membranes supported on different substrates such as $\alpha$-alumina, $\gamma$-alumina, zirconia or porous stainless steel. The porous inorganic membranes can be further classified based on their pore size (microporous $(<2 \mathrm{~nm})$ or mesoporous $(>2 \mathrm{~nm}$ to $<50 \mathrm{~nm}$ ) or macroporous $(>50 \mathrm{~nm})$ ) or symmetry and asymmetry. Lange et al. (1995) classified the microporous inorganic membranes based on synthesis route and material. According to them, the main types of microporous inorganic membranes are: (1) sol gel derived ceramic membranes, (2) chemical vapour deposition (CVD) modified (glass or ceramic) membranes, (3) leached hollow glass fibers (phase separation technique), (4) carbon molecular sieves membranes and (5) zeolite membranes.

The dense inorganic membranes (non porous material) consist of a thin layer of metal, such as palladium and its alloys (metallic membranes), or solid electrolytes such as zirconia. These membranes are highly selective for hydrogen separation: the transport of particles occurs by solution-diffusion method or charged particles in dense membranes. The low permeability across the dense inorganic membranes limits its intended applications as compared to porous inorganic membranes. Another form of inorganic membrane is the liquid-immobilized membrane, where the pores of a membrane are completely filled with a liquid, which is permselective for certain compounds. The liquid reacts with the permeating component on the feed side to form a complex. The complex diffuses across the membrane, then releases the permeant on the product side and converts the liquid back to the feed side simultaneously. Currently, industrial and academic laboratories are studying experiment in the inorganic membrane area. Inorganic membranes have a high potential for gas separation at high temperatures in chemically aggressive environments. A possible application for these membranes is in high-temperature membrane reactors. The advantages and disadvantages of inorganic membrane and polymeric membrane are compared in Table 3. It can be seen from Table 3 that inorganic membranes show advantages such as stability at high temperatures and resistance towards solvents. These promising advantages are the driving force for solving problem such as high production cost. Caro et al. [6] provided a technical overview of inorganic membranes in their paper. They discussed the preparation of inorganic membrane and their applications. The other publication that discussed the overviews of inorganic membranes is by Lin et al. [7]. The authors reported recent significant progress in the synthesizing of microporous and dense inorganic membranes. They also described several methods for synthesis of microporous amorphous and polycrystalline (zeolite) inorganic membranes and their major characteristics.

Table 3 Comparison of inorganic membrane and polymeric membrane

\begin{tabular}{ll}
\hline Inorganic membranes & Polymeric membranes \\
\hline Long term stability at high temperatures & High capital costs \\
Resistance to harsh environments & Brittleness \\
Resistance to high pressure drops & Difficulty in achieving high selectivities \\
Easy catalytic activation & Difficult membrane-to-module sealing at high \\
& temperatures \\
\hline
\end{tabular}




\subsubsection{Alumina Membranes}

The general mesoporous structure of alumina dictates that transport within membranes fabricated from it will take place by a Knudsen diffusion mechanism [8]. Since selectivity in this regime is limited, and the rate of diffusion is controlled by molecular weight, alumina membranes have limited use in the separation of gases. With mixtures such as $\mathrm{CO}_{2} / \mathrm{N}_{2}$ where the gases have similar mass, and $\mathrm{CO}_{2} / \mathrm{H}_{2}$, where selectivity towards the heavier component is required, alumina is undesirable as a membrane material. Alumina is mainly favourably used as a support in gas separation because of its sound structural as well as its chemical and hydrothermal stabilities. A few attempts to modify alumina membranes in order to facilitate $\mathrm{CO}_{2}$ surface diffusion met with limited success. To achieve high' separation factors in systems like $\mathrm{CO}_{2}$ and $\mathrm{N}_{2}$, a good interaction between one of the gases in the mixture and the membrane surface can be developed by chemical modification of separation layers.

Nijmeijer et al. [9] modified a $\gamma$-alumina membrane system using low temperature chemical vapor infiltration (CVI). They observed that the modification on the performance of $\gamma$-alumina membranes with a $0.5 \mathrm{~mol} \%$ silane mixture did not significantly increase the selectivity of membranes. This phenomenon was attributed by the reaction temperature or concentration of silane in the mixture being too low. Pan et al. [10] studied the modification of nanoporous alumina using chemical vapour deposition (CVD) by introducing trimethylaluminum and water vapour to improve the performance of membrane. The performance of the modified membrane increased in terms of water/oxygen selectivity compared to unmodified membrane. The authors concluded that the atomic layer of CVD process was an effective means for the modification of nanoporous ceramic membranes.

The performance of modified Titania membrane coating with alumina for $\mathbf{H}_{2}$ separation was investigated by Ahmad et al. [11]. They studied the effect of feed rate, feed concentration and average pressure on permeability of binary hydrogen mixture. They reported that the surface diffusion and the permeability of membrane were reduced at higher temperature, particularly for nitrogen gas. They observed that the separation process was dominated by Knudsen diffusion mechanism. They also found that the permeability of the gases across perm-selective alumina layer was higher than that across titania and composite membranes.

\subsubsection{Zeolite Membranes}

Zeolites are crystalline aluminosilicates with a uniform pore structure and a minimum channel diameter ranging from 0.3 to $1.0 \mathrm{~nm}$. The presence of molecular-sized cavities and pores make the zeolites effective as shape-selective materials for a wide range of separation applications. These cavities are interconnected by pore openings through which molecules can pass. The electrical charge or polarity of the zeolites functions to attract or sort molecules. The ability to selectively adsorb molecules by size and polarity is the key to the unusual efficiency of synthetic zeolites and the basis for separation to occur. Zeolite membranes have been usually prepared by in situ hydrothermal synthesis on porous stainless steel, $\alpha$-alumina, or $\gamma$-alumina support tubes or disks for the gas permeation studies. These supported zeolite membranes have a thin and continuing zeolite separation layer with the porous support providing mechanical strength to the membrane. The most often prepared zeolite membrane is MFI $[6,7,12]$. The main reasons are the accumulated knowledge in the synthesis of the MFI structure, the suitable pore diameter of $0.55 \mathrm{~nm}$, which is interesting for industrial applications, the relatively ease of preparation, the possible modifications in the chemical compositions including cation exchange and last, but not least, a relatively high thermal and chemical stability due to the high $\mathrm{SiO}_{2} / \mathrm{Al}_{2} \mathrm{O}_{3}$ ratio. The important factors of zeolite membrane separation are molecular sieving and surface diffusion that is caused by the pore size. In zeolite membranes, both 
molecular sizes relative to the zeolite pore and the relative adsorption strengths determine the faster permeating species in a binary mixture. The separation ability of a microporous membrane can be described by the interplay of the mixture adsorption equilibrium and the mixture diffusion in a way similar to the solubility-diffusivity model established for describing the permeation behavior of organic polymer membranes.

Hasegawa et al. [13] applied the alkali metal to prepare $\mathrm{NaY-zeolite} \mathrm{membrane} \mathrm{for} \mathrm{CO}_{2}$ separation. They reported that the performance of the membrane was affected by exchanged cations. In a further investigation, Hasegawa et al. [13] studied the effect of temperature on the gas separation properties of NaY-zeolite membrane. They observed that the membranes were stable when subjected to heat at temperatures up to $400^{\circ} \mathrm{C}$ and the permeation reached a maximum indicating that the permeance was dependent on the heat of adsorption. They also reported that the permeation mechanism could be explained using the Maxwell-Stefan diffusivities model.

Li et al. [14] prepared the SAPO-34 membrane with low concentration of zeolite using in situ crystallization on porous stainless steel and $\gamma-\mathrm{Al}_{2} \mathrm{O}_{3}$ supports. They observed that the membrane permeability for $\mathrm{CO}_{2}$ was higher than $\mathrm{CH}_{4}$. This is because $\mathrm{CO}_{2}$ preferentially adsorbs and it also diffuses faster than $\mathrm{CH}_{4}$. They also observed that the selectivity was dependent on temperature, feed pressure and pressure drop. Chen et al. (2005) synthesized NaA-zeolite membrane using microwave heating on macroporous substrate, a combination of mesoporous/macroporous substrate in gel and on mesoporous/macroporous in sol. They found that the $\mathrm{H}_{2}$ permeance of the $\mathrm{NaA}$-zeolite membranes prepared by microwave heating in gel was much higher than the other membrane. Giannakopoulos and Nikolakis [15] investigated the performance of faujasite-zeolite membrane to separate mixtures of propylene/propane. The zeolite membranes were synthesized using the secondary growth method on porous $\alpha-\mathrm{Al}_{2} \mathrm{O}_{3}$ disk support prepared by pressing commercial $\alpha-\mathrm{Al}_{2} \mathrm{O}_{3}$ powder. They proved that the faujasite type zeolite improved the performance of membrane. The separation factor achieved was 13.7 at $100^{\circ} \mathrm{C}$ and the selectivity was 28 at $35^{\circ} \mathrm{C}$, respectively.

For future study, the development of zeolite membranes should be addressed in the preparation of composite membranes consisting of a thin $(<1 \mu \mathrm{m})$ zeolite layer on a mesoporous ceramic or metal support.

\subsubsection{Silica Membrane}

Silica membranes have been known for about a decade. They can be used in many applications such as gas separation, liquid separation and pervaporation. Unlike alumina, which tends to undergo phase transition at relatively low temperatures, silica shows exceptional thermal, chemical, and structural stability in both oxidizing and reducing environments. Although fabrication procedures are not as advanced as those for carbon and alumina membranes, they are capable of producing defect-free silica membranes with molecular sieving pores. The gas transport mechanism of silica has been dominated by molecular sieving. The major problem of silica membranes suffering water sorption sensitivity at room temperature is due to the hydrophilic nature of the silica surface. Sorption of moisture, for instance from air, can result in pore blocking with a large impact on separation properties. Interaction of the membrane with water from process streams at higher temperatures can result in serious degradation phenomena.

Currently, the studies of silica membrane have addressed primarily on separation of $\mathrm{CO}_{2}$ from $\mathrm{N}_{2}$ and $\mathrm{CH}_{4}$. Many studies synthesized the silica membrane using the sol-gel method, the most common type of preparation procedure for silica membranes. Silica is a very versatile material for gas separation membranes because its structure can be tailored by changing the preparation method and conditions. Generally, microporous silica membranes are prepared by the deposition of a silica layer onto a porous support by either the sol-gel method, or chemical vapour deposition (CVD) technique, or 
phase separation method. The porous support provides mechanical strength to the selective top layer of silica. de Vos and Verweij [16] studied the silica membrane from tetraethyl orthosilicate using sol-gel method. The authors applied two silica layers on top of a $\gamma$-alumina layer that was supported by $\alpha$-alumina support. They observed that the permeance of $\mathrm{H}_{2}, \mathrm{CH}_{4}, \mathrm{~N}_{2}$ and $\mathrm{O}_{2}$ gas increased slightly with increasing temperature but the permeance of $\mathrm{CO}_{2}$ decreased slightly with increasing temperature. In a further study, de Vos et al. [17] studied the hydrophobic silica membranes for gas separation. They observed that the properties of microporous silica membranes changed significantly with the incorporation of methyl group in the silica microstructure. Therefore, the water could be removed easily and the membrane could be applied in humid process streams.

Kusakabe et al. [18] studied the polymeric silica membrane using sol-gel technique. The silica sol membranes were deposited on top of a support system consisting of about a micron thick of $\gamma$-alumina over a macroporous $\alpha$-alumina of desired thickness. The silica layer was then calcined at 400 to $800^{\circ} \mathrm{C}$, and end up as the separating top layer with thickness of 50 to $100 \mathrm{~nm}$. The silica sols were obtained from the hydrolysis condensation reaction of alkoxysilanes, such as tetramethoxysilane (TMOS), tetraethoxysilane (TEOS), or chlorosilane. Silica membranes prepared on $\gamma$-alumina coated with $\alpha$-alumina tube using a sol-gel technique was studied by Kusakabe et al. [19]. They used methacryloxypropyl trimethoxysilane (MOTMS) in the ethanol solution of tetraethyl orthosilicate (TEOS) to control the pore structure in the formation of the silica sol. They observed that the modified membranes showed higher selectivity compared to unmodified membrane. They also reported that the membrane separation properties of $\mathrm{H}_{2} / n-\mathrm{C}_{4} \mathrm{H}_{10}$ increased due to the surface modification. Currently, the silica membranes are applied for gas separation and pervaporation [20]. They prepared their membrane on the outer surface of hollow fiber ceramic substrates. They observed that the effect of hollow fiber substrate to the overall mass transport resistance was small. They also applied the membrane for the dehydration of $\mathbf{n}$-butanol at $80^{\circ} \mathrm{C}$ and $5 \mathrm{wt} \%$ water. In addition, they found that a high flux and selectivity were observed at $2.9 \mathrm{kgm}^{-2} \mathrm{~h}^{-1}$ and 1200 , respectively.

\subsection{Polymer Membranes}

Two types of polymeric membranes are widely used commercially for gas separation. Glassy polymers are rigid and operate below their glass transition temperatures. On the other hand, rubbery membranes are flexible, soft and operate above their glass transition temperatures. Generally, polymeric membranes exhibit an inverse permeability/selectivity behavior. In another hand, selectivity of too different gas pairs increases as the gas permeability decreases and vice versa. Most rubbery polymers show a high permeability, but low in selectivity, whereas glassy polymers exhibit a low permeability but high in selectivity. Glassy polymeric membranes dominate industrial membrane separation because of their high gas selectivities, along with good mechanical properties.

\subsubsection{Rubbery Polymer Membranes}

There are not many rubbery polymers other than silicone polymers that can be used in gas separations. Tanioka et al. [21] investigated the effects of carbon filler on the sorption and diffusion of carbon dioxide in natural rubber and in styrene-butadiene rubber. They reported that the isotherms in filled rubber exhibited a combination of the two sorption modes. They found that the diffusion coefficient decreases with increasing filler content. This phenomenon occurred due to the geometric and polymer chain immobilization in the interfacial regions. Sada et al. [22] studied the permeability of $\mathrm{CO}_{2}$ and $\mathrm{CH}_{4}$ in the polyethylene membranes at a 20,30 and $40^{\circ} \mathrm{C}$. They found that the pressure dependence of the logarithms of permeability coefficients became linear except for the $\mathrm{CO}_{2}$ - polyethylene system, 
where the pressure dependence became quadratic, with a minimum at a certain value of pressure. The coefficients of sorption and dilation isotherms and diffusion for $n$-butane, isobutane, 1 -butene, cis-2-butene, trans-2-butene, isobutylene, and 1,3-butadiene in two rubbery polymers, 1,2polybutadiene ( $\mathrm{PB}$ ) and poly (ethylene-co-vinyl acetate) (EVAc) at $25^{\circ} \mathrm{C}$ were reported by Kamiya et al. [23]. 1,2-polybutadiene (PB) exhibited greater affinity and lower diffusivity than EVAc to the $\mathrm{C}_{4}$ gases, although the gases showed nearly the same partial molar volumes in the two polymers. The diffusivity of elongated molecules such as trans-2-butene in both polymers was higher than that of bulky molecules with similar partial molar volume, such as cis-2-butene and isobutylene.

Ettouney and Majeed [24] studied the effect of driving pressure for polysulfone and rubber membranes for pure gases and mixtures of $\mathrm{N}_{2}-\mathrm{O}_{2}, \mathrm{CO}_{2}-\mathrm{N}_{2}$ and $\mathrm{CH}_{4}-\mathrm{N}_{2}-\mathrm{CO}_{2}$. The functions were expressed in a linear form in terms of species partial pressures and in good agreement with the measured data. Positive and large weights for the fastest permeating species, $\mathrm{CO}_{2}$, were obtained in the permeability functions for all species in polysulfone. The permeability of poly (dimethylsiloxane) (PDMS) and poly(1-trimethylsilyl-1-propyne) (PTMSP) for a simulated syngas feed containing $\mathrm{H}_{2}$, $\mathrm{CO}, \mathrm{CO}_{2}$, and $\mathrm{H}_{2} \mathrm{~S}$ as a function of temperature up to $240^{\circ} \mathrm{C}$ was studied by Merkel et al. [25]. They reported that the permeation of $\mathrm{CO}$ and $\mathrm{H}_{2} \mathrm{~S}$ were consistent with their molecular properties. The membranes were more permeable to the condensable gases such as $\mathrm{CO}_{2}$ and $\mathrm{H}_{2} \mathrm{~S}$ compared to $\mathrm{H}_{2}$ at room temperature. However, both polymer membranes became $\mathrm{H}_{2}$ selective at elevated temperatures. Activation energies of permeation were highest for $\mathrm{H}_{2}$ in both polymers and decreased regularly with increasing gas condensability. PTMSP exhibited acceleration of physical aging at high temperature. Polyphosphazenes are hybrid polymers that consist of highly flexible inorganic phosphorus-nitrogen backbone with two functional groups. The inorganic backbone provides thermal and chemical stability to the polymer. They are thermally stable up to $400^{\circ} \mathrm{C}$ [26].

Orme et al. [26] investigated polyphosphazenes with three different functional groups of different hydrophilicity for the gas separation. Functional groups attached are 2-(2-methoxyethoxy)ethanol (MEE) that provides a polar hydrophilicity, 4-methoxyphenol (4MP) that offers hydrophobicity and film forming abilities, and 2-allylphenol (2AP) for cross-linking. $\mathrm{CO}_{2}$ permeability increased linearly with amount of hydrophilic MEE on the polymer backbone. They attributed this behavior to strong intermolecular interaction between $\mathrm{CO}_{2}$ and the MEE group. Feng et al. [27] investigated gas permeation through poly (dimethyl siloxane) coated polysulfone hollow fiber composite membranes. The permeance of the composite hollow fiber membranes was found to be constant at a given temperature over the test pressure range $(100-5000 \mathrm{kPa})$. They reported that there were three major possible mechanisms for gas permeation through a membrane: solution-diffusion, Knudsen diffusion and viscous flow. They also suggested that the membranes must posses mechanical strength that is able to withstand the mechanical stress applied to the hollow fibers while pressure differential across the fiber wall has little effect on the membrane structure. Raptis et al. [28] studied the molecular dynamics simulation model to comprehend the structure and thermodynamic properties of a novel rubbery polymer membrane. A realistic united atom force field was developed based on density of functional and theories of quantum mechanics were applied on a Dimer model and volumetric data at various temperatures and pressures. The microscopic structure of the free volume of the polymer matrix and its evolution with time affected the diffusion of penetrant molecules considerably; they can be calculated accurately using the Greenfield and Theodorou geometric analysis.

\subsubsection{Glassy Polymer Membranes}

Kawakami et al. [29] investigated the permeability of cellulose nitrate ( $\mathrm{CN}) /$ poly (ethylene glycol) (PEG) blend membranes for $\mathrm{N}_{2}, \mathrm{O}_{2}$, and $\mathrm{CO}_{2}$. They found that the CN/PEG 300 system showed excellent miscibility, and films of the composition from 100/0 to 50/50 could be used for permeability 
test. The permeability of membranes were almost constant and lowered up to the composition of $20 \mathrm{wt} \%$ PEG-300 content and then increased appreciably with increasing fraction of PEG. The authors also reported that the phenomenon of plasticization occurred in the CN/PEG blend membranes. Matsumoto and $\mathrm{Xu}$ [30] synthesized two hexafluoro-substituted aromatic polyimides, 6-FDA-pPDA and 6FDA-4.4'-ODA, for gas permeation studies at $15-35^{\circ} \mathrm{C}$ and at pressures up to 10 atm. They used the solution-casting method to fabricate the asymmetric membranes. They achieved higher gas permeabilities through 6FDA polyimides, compared to PMDA polyimides, though high permselectivities of 6FDA polyimides were maintained. They suggested that a helix configuration contributed to the increase in the free volume of the polymer, due to the bulky $-\mathrm{C}\left(\mathrm{CF}_{3}\right)_{2}-$ group in the polymer backbone. Hence, it controlled the gas diffusivity. Costello et al. [31] studied polypyrrolone material, hexafluorodianhydride-3,3',4,4'-tetraaminodiphenyl oxide (6FDA-TADPO), for membranebased gas separations at elevated temperatures. It was reported that the solubility and diffusivity selectivity of various gas pairs decrease with increasing temperature. They observed that the solubility selectivity of gas pairs with the 6FDA-TADPO membrane was almost unaffected by temperature increase. Therefore, the loss of permselectivities was entirely from the loss of the diffusivity selectivity at elevated temperature. It was concluded that the diffusivities of larger molecules benefited more from increased polymer chain motion due to increasing temperature. Thus, the $\mathrm{CO}_{2} / \mathrm{CH}_{4}$ (size difference $0.5 \AA$ ) selectivity decreased more rapidly with increasing temperature than the $\mathrm{CO}_{2} / \mathrm{N}_{2}$ (size difference $0.34 \AA$ ) selectivity.

Aromatic polyimide membranes from 2,2'-bis(3,4-dicarboxyphenyl) hexafluoropropane dianhydride (6FDA) and 3,3'-diaminodiphenylsulfone (m-DDS) were synthesized by Kawakami et al. [32] to facilitate the study of relationships between the polymer structure and the gas transport properties of $\mathrm{O}_{2}, \mathrm{~N}_{2}, \mathrm{CO}_{2}$ and $\mathrm{CH}_{4}$. The membranes were prepared by the solvent-casting method and then cured at 150,200 , and $250^{\circ} \mathrm{C}$. They discovered that the packing density and the fluorescence intensity of the 6FDA-m-DDS polyimide increased sharply with the increasing curing temperature. It was concluded that this behavior was associated with an increase in intermolecular and/or intramolecular interactions by a charge transfer complex formed in 6FDA-m-DDS containing an alternating sequence of electron donor and electron acceptor molecules.

Polyimides are very attractive membrane materials for gas separations because of their good gas separation and physical properties such as high thermal stability and chemical resistance. Numerous works have been conducted to alter the chemical structure of polyimide, aiming to get both high permeable and selective membrane materials. However, problems associated with the swelling and plasticization of polyimide can limit its applications in the gas separation area. The polymer matrix swelled upon sorption of $\mathrm{CO}_{2}$ that was present in the feed and accelerated the permeation of other species in the feed. Consequently, the selectivity of the polymer membrane reduced. In order to overcome this effect, plasticization should be minimized. Therefore, many researchers used the crosslinking methods to solve the plasticization or swelling problem to enhance the permeability properties of the polyimide membranes[33-37].

Hirayama et al. [35] synthesized polyethylene oxide crosslinked polymer membrane from poly(ethylene glycol) dimethacrylate (DM), 2,2-bis (4-methacryloxy polyethoxy phenyl)propane and poly(ethylene glycol) methyl ether methacrylate (MM) by photo polymerization. They reported that the membrane films had high polyethylene oxide content that caused high $\mathrm{CO}_{2}$ permeability and high $\mathrm{CO}_{2} / \mathrm{N}_{2}$ selectivity in comparison to other polymers. The high $\mathrm{CO}_{2} / \mathrm{N}_{2}$ selectivity was attributed to the high solubility selectivity due to the affinity of the $\mathrm{PEO}$ segment for $\mathrm{CO}_{2}$. The introduction of phenylene rings to the polymer chain decreased $\mathrm{P}_{\mathrm{CO} 2}, \mathrm{D}_{\mathrm{CO} 2}, \mathrm{P}_{\mathrm{CO} 2} / \mathrm{P}_{\mathrm{N} 2}$ and $\mathrm{S}_{\mathrm{CO} 2} / \mathrm{S}_{\mathrm{N} 2}$ because of both reductions in the segmental motion and in the affinity of $\mathrm{PEO}$ for $\mathrm{CO}_{2}$. Li et al. [38] prepared polyethylene glycol/cellulose acetate blend membranes for gas separation studies. The permeabilities of $\mathrm{CO}_{2}, \mathrm{H}_{2}, \mathrm{O}_{2}, \mathrm{CH}_{4}$, and $\mathrm{N}_{2}$ were measured at temperatures from 30 to $80^{\circ} \mathrm{C}$ and pressures from 20 
to $76 \mathrm{cmHg}$ using a manometric permeation apparatus. The blend membranes containing 60\% PEG 2000 showed high apparent $\mathrm{CO}_{2}$ diffusivity coefficients, resulting in higher permeability for $\mathrm{CO}_{2}$ than that of the cellulose acetate membrane. Therefore, they concluded that the flexible main chain of PEG20000 in the amorphous domains in the blend allowed large penetrant $\mathrm{CO}_{2}$, and $\mathrm{CH}_{4}$, to diffuse easily through the blend membranes, resulting in higher permeance of $\mathrm{CO}_{2}$ and $\mathrm{CH}_{4}$ relative to $\mathrm{N}_{2}$. However, the $\mathrm{CO}_{2} / \mathrm{CH}_{4}$ selectivities was lower as PEG20000 was blended with CA. Bos et al. [39] investigated the cross-linking of Matrimid polymer membrane by a thermal treatment at $350^{\circ} \mathrm{C}$ in order to reduce the $\mathrm{CO}_{2}$ plasticization. They reported that the plasticizing effect accelerated the permeation of methane for $\mathrm{CO}_{2} / \mathrm{CH}_{4}$ gas mixture in the untreated membrane. However, $\mathrm{CH}_{4}$ and $\mathrm{CO}_{2}$ permeation remained constant for heat-treated matrimid membranes.

Staudt-Bickel and Koros [40] prepared uncrosslinked and crosslinked polyimides and copolyimides to reduce the effect of swelling and plasticization due to $\mathrm{CO}_{2}$ in $\mathrm{CO}_{2} / \mathrm{CH}_{4}$ separation. They used 6 FDA as dianhydride monomer and $\mathrm{mPD}$ (m-phenylene diamine) and DABA (diamino benzoic acid) as diamine monomer for the polymerization reaction. The experimental results showed that the plasticization decreased with copolyimides containing strong polar carboxylic acid (6FDA- mPD/ DABA 9:1) for a pure $\mathrm{CO}_{2}$ feed with pressure up to $14 \mathrm{~atm}$. The reduction was attributed to chemical cross-linking caused by hydrogen bonding between the carboxylic acid groups. They observed that the swelling effects caused by $\mathrm{CO}_{2}$ could be reduced to $35 \mathrm{~atm} \mathrm{CO}_{2}$ feed pressure by chemical crosslinking of the free carboxylic acid groups of the 6FDA- $m$ PD/DABA 9:1 with ethylene glycol. They also observed that the $\mathrm{CO}_{2} / \mathrm{CH}_{4}$ selectivity increased with increasing degree of cross-linking because of reduced swelling and polymer chain mobility. The $\mathrm{CO}_{2}$ permeability was not significantly affected by cross-linking with ethylene glycol because the reduced chain mobility was compensated by the additional free volume.

Shieh et al. (2000) studied cellulose nitrate (CN)-based composite hollow fiber for gas separation. They investigated the effect of coating solution, polysulfone (PS) substrate, pre-wetting treatment, solvent and the various substrate material in the performance of membrane. The performance of membrane was not significantly affected by pre-wetting treatment because of the coating technique and the relatively high permeable substrate. Interestingly, the solvent used in dissolving cellulose nitrate really affected the selectivity property of the multilayer composite membrane. This effect might be caused by the formation of different membrane morphology of cellulose membrane layer that was ascribed to the different physical properties of solvents. The membrane performance was improved by coating $\mathrm{CN}$ between the silicone rubber and PS substrate that reduced the surface defects on the composite hollow fiber. The lower $\mathrm{O}_{2} / \mathrm{N}_{2}$ selectivity of the multilayer composite hollow fiber compared to $\mathrm{CN}$ on the literature suggested that $\mathrm{CN}$ might exhibit a facilitated transport for $\mathrm{O}_{2}$ or that the $\mathrm{CN}$ coating was ineffective in improving the performance of the PS substrate used in this study. The surface porosity and roughness of PS hollow fiber substrates affected the formation of a $\mathrm{CN}$ coating layer. Substrates with limited defects and a smoother surface improved the performance of the resultant multilayer composite membranes. Furthermore, Shieh et al. [41] prepared multilayer composite membrane with the permeable sealing that was applied to plug the remaining defects in the coated selective layer. They used silicone rubber as the sealing material and poly(4-vinylpyridine) as the selective layer and polyetherimide hollow fiber as the support substrate. They discovered that the addition of PEG to PEI spinning dopes effectively suppressed the growth of macro-voids. A more porous surface with a more compact cellular structure was obtained for PEI hollow fibers made from dopes with a high PEG content. Gas permeation data suggested that the skin layer resistance decreased as the substructure resistance increased with the increasing of PEG content in the spinning dope. Composite hollow fiber membranes, P4VP/ PEI, exhibited a Knudsen mechanism, suggesting that a perfect thin P4VP layer did not form on the PEI hollow fibers without SR, which was the sealing layer material. 
It has been extensively reported in the literature that aromatic polyimides containing $-\mathrm{C}\left(\mathrm{CF}_{3}\right)_{2}-$ groups in their dianhydride moieties (e.g., $6 \mathrm{FDA}$-based polyimides) are identified to be more gasselective, particularly towards $\mathrm{CO}_{2}$ relative to $\mathrm{CH}_{4}$ and $\mathrm{N}_{2}$, than other glassy polymers. Hirayama et al. [42] studied the gas permeability properties of different polyimides, which were synthesized from the reactions of various diamines containing biphenyl, diphenyl, diphenylmethane, phenylether, diphenyl sulfone, or diphenyl sulfide with BPDA, 6FDA, or PMDA. They also investigated the relation of gas permeabilities, diffusivities, solubilities and the structures of various polyimide films. It was concluded that the diffusivities of amorphous polyimides did not correlate with the intersegmental spacing parameters (d-spacing and fractional free volumes), particularly for polyimides containing polar substituents.

Suzuki et al. [43] prepared composite hollow fiber membranes composed of a thin film and dense outer layer poly (ethylene oxide)-containing BPDA-PEO3/ODA polyimide and a sponge-like inner layer BPDA-ODA/DABA polyimide. The composite membranes were prepared by a dry-jet wet spinning process using a double layer spinneret. The $1 \mu \mathrm{m}$ thick of outer layer was responsible for gas separation. The $\mathrm{CO}_{2}$ permeability and the $\mathrm{CO}_{2} / \mathrm{N}_{2}$ selectivity were decreased by $40 \%$ and 10 to $20 \%$, respectively, a month after the membrane preparation. Therefore, the reduction of membrane performance was caused by densification of the inner layer at the interface to the outer layer, which might be caused by a plasticization effect of the PEO-containing polyimide. The $\mathrm{CO}_{2} / \mathrm{N}_{2}$ separation performance was significantly dependent on temperature; it performed better at lower temperature, because the selectivity decreased sharply with increasing temperature, whereas $R_{\mathrm{CO} 2}$ increased moderately or slightly.

Tokuda et al. [44] investigated a Cardo polyimide for carbon dioxide separation. Cardo polyimides membranes showed higher $\mathrm{CO}_{2} / \mathrm{N}_{2}$ selectivities than those of other polymeric membranes. They used a bulky bis-phenylfuluorene as a Cardo polyimide. It was discovered that the Cardo polyimides had some specific characteristics, such as high gas permeability, high heat resistivity, and a high solubility in organic solvents. The Cardo polyimides, particularly those with $3,3^{\prime}, 4,4^{\prime}$-benzophenonetetracarboxylic dianhydride as a monomer (PI-BT), gave highest $\mathrm{CO}_{2} / \mathrm{N}_{2}$ selectivity. The selectivities of $\mathrm{CO}_{2} / \mathrm{N}_{2}$ for Cardo polyimide (PI-BT-COOMe) could be reached up to 52 at $25^{\circ} \mathrm{C}$. The $\mathrm{CO}_{2} / \mathrm{N}_{2}$ selectivity was improved by introducing a $\mathrm{CO}_{2}$ affinitive functional group on the Cardo constitution. Tokuda et al. [44] also developed a wet-spinning method to produce asymmetric hollow fibers with less inner skin layers defects from PI-BT-COOMe. These hollow fiber membranes reached the maximum $\mathrm{CO}_{2} / \mathrm{N}_{2}$ selectivity of 40 , with a permeance of $1.5 \times 10^{-4} \mathrm{~cm}^{3}$ (STP) $\mathrm{cm}^{-2} \mathrm{~s}^{-1} \mathrm{~cm} \mathrm{H}^{-1}$ at $25^{\circ} \mathrm{C}$, and a good mechanical strength. The term "Cardo-polymers" was proposed in 1971 by Korshak [44] to designate at least one part of the constitutive unit, which carries a lateral ring connected to the main macromolecular backbone by a quaternary carbon atom. The presence of Cardo groups induces some specific properties to all polymers, including such groups. Thermal characteristics, glass transition temperature, and heat resistance are the characteristics of rigid macromolecules, but with significantly enhanced solubility in organic solvents and high transition temperatures.

The permeation behavior of water vapor, $\mathrm{H}_{2}, \mathrm{CO}_{2}, \mathrm{O}_{2}, \mathrm{~N}_{2}$, and $\mathrm{CH}_{4}$ gases in a series of novel poly (aryl ether sulfone)s was discussed by Wang et al. [45]. The authors used four alkyl-substituted cardo poly (aryl ether sulfone)s and four intermolecular interaction enhanced poly(aryl ether sulfone)s. They observed that the bulky alkyl substituents on the phenylene rings the advantages to gas permeability, while the intermolecular hydrogen bonds and ionic bonds resulted in a considerable increase in gas selectivity. It was concluded that the modified membrane displayed both higher permeabilities and higher selectivities compared to those of the unmodified PES. Kim et al. [46] synthesized composite membranes using pore-filling concept. The membrane composed of two polymeric materials; polyacrylonitrile membrane as a porous substrate and methoxy poly(ethylene glycol) acrylate (MePEGA) as a filling polymers using UV irradiated photografting. They observed 
high $\mathrm{CO}_{2} / \mathrm{N}_{2}$ selectivity (32.4) from this pore-filling membrane at $30^{\circ} \mathrm{C}$ with very low $\mathrm{CO}_{2}$ permeability of $5.65 \mathrm{GPU}$. The high selectivity of the membrane was attributed to high solubility selectivity caused by the affinity of $\mathrm{CO}_{2}$ to PEO segments. They concluded that the substrate contributed to the mechanical and thermal stability of the whole membrane and the grafted PEO contributed to a very high $\mathrm{CO}_{2} / \mathrm{N}_{2}$ separation.

The $\mathrm{CO}_{2}$ plasticization of gas separation hollow fiber membranes based on polyimide and polyethersulfone blends was studied by Kapantaidakis et al. [47]. They encountered that the permeability of pure gas $\mathrm{CO}_{2}$ and $\mathrm{N}_{2}$ and the separation performance of a gaseous mixture was affected by the feed pressure. Liu et al. [48] studied the effect of chemical cross-linking of polyimide/ poly (ethersulfone) on the dual layer hollow fiber membranes for gas separation. They used a polyimide copoly[1,4-durene/1,3-phenylene-2,2-bis (3,4-dicarboxyphenyl) hexafluoro propanediimide] (6FDAdurene/mPDA) (50:50) as the outer layer and poly(ether sulfone) (PES) as the inner layer. They applied immersing method to produce chemical cross-linking modification on the outer layer using $5 \%$ (w/v) $p$-xylenediamine/methanol solution at ambient temperature. The Fourier transform infrared showed that the chemical cross-linking modification occurred as the formation of amide groups through the reactions between $p$-xylenediamine and imide groups. They reported that this modification caused decreases in gas permeation rates for $\mathrm{CO}_{2}, \mathrm{CH}_{4}, \mathrm{O}_{2}$, and $\mathrm{N}_{2}$. However, the separation factors of $\mathrm{CO}_{2} / \mathrm{N}_{2}$ and $\mathrm{CO}_{2} / \mathrm{CH}_{4}$ showed a significant increase after the modification.

Mi et al. [49] investigated the effect of plasticization by small molecules as the glass transition temperature was reduced. They discovered that diffusion coefficients of small molecules on the penetrant concentration were affected by the reduction of the glass transition of polymer. They agreed that this phenomenon was caused by the plasticization effect of the penetrant. Wind et al. [50] reported that the esterification reaction of 6 FDA-based polyimide was effective in stabilizing membranes against $\mathrm{CO}_{2}$ plasticization up to $40 \mathrm{~atm}$ feed pressure. They agreed that the selection of cross-linking agent had a major impact on the gas transport properties. They also found that the annealing temperature was a significant factor in determining the membrane transport properties, since it affected the polymer chain rigidity and free volume distribution. Chung et al. [37] studied PAMAM dendrimer generation as the novel cross-linking agent at ambient temperature. The crosslinking was formed through the reaction between the amine groups of dendrimers and imide groups of polyimide. They discovered that the modified polyimide membrane good chemical and physical stability but also excellent permeability and selectivity. The $\mathrm{CO}_{2}$ permeability increased after the modification, mainly due to a significant increase of solubility in the cross-linked polymer that was caused by the interactions between dendrimer and $\mathrm{CO}_{2}$, and dendrimer-induced interstitial change in polymer chains.

Recently, several attempts have also been made to predict gas permeability and selectivity in polymeric materials [51-53]. Robeson et al. [51] studied a group contribution method to predict the permeability and selectivity of aromatic polymer such as polysulfone, polycarbonate and polyimide. They found the method that can be used to predict the permeability of $\mathrm{O}_{2}, \mathrm{~N}_{2}$ and $\mathrm{He}$ very well. They did not use the fractional free volume approach like Park et al. [53]. Unfortunately, their study was only limited to the $\mathrm{O}_{2} / \mathrm{N}_{2}$ and $\mathrm{He} / \mathrm{N}_{2}$ gas pairs. Park et al. [53] used a modified free volume based on group contribution method for predicting the permeability of six common gases $\left(\mathrm{He}, \mathrm{H}_{2}, \mathrm{O}_{2}, \mathrm{~N}_{2}\right.$, $\mathrm{CH}_{4}$, and $\mathrm{CO}_{2}$ ) in glassy polymers. The method predicted the polymer density and employed a modified estimate of a specific free volume to each gas. Various empirical group contribution factors in the model were deduced from a database of specific volume and permeability for over one hundred glassy polymers. Thran et al. [54] studied the correlation between the diffusivity of gas molecules in glassy polymer and the fractional free volume using the Bondi method. They concluded that the diffusion mechanism of $\mathbf{H}_{2}$ and particularly $\mathrm{He}$ differed markedly from that of larger gas molecules. They also discussed the influence of the cohesive energy and the glass transition temperature of the polymers. Alentiev et al. [52] also used the group contribution method to predict the gas permeation 
parameters (permeability and diffusion coefficients) of glassy polymers. They deduced the group contributions from a database, including about 120 polyimides prepared from nine different dianhydrides, and about 70 diamines.

\subsection{RECENT DEVELOPMENT OF MEMBRANE MATERIALS FOR GAS SEPARATION}

Currently, for the membrane applications more severe selecting criteria are required for membrane materials. In fact, recent membrane processes under industrial development (gas separation, pervaporation, nanofiltration) are mostly dealing with the separation of very small entities (ions or molecules) whether in gas, vapor or liquid phases. In certain processes, membranes are the interface of two different phases (pervaporation, membrane distillation). In addition, a reaction was coupled with the separation (catalytic membrane reactors). Inexpensive fabrication techniques that can produce defect-free membrane should be available from a variety of configurations of materials. Stability at elevated temperatures is also a compulsory. The selective membrane thickness is a crucial parameter, because thicker membranes directly resulted in higher material costs and lower membrane flux. Lower flux represents lower membrane productivity and, hence, increasing the operating costs. An example of membrane separation challenge in the recent years is to separate $\mathrm{CO}_{2} / \mathrm{CH}_{4}$ gas. The small difference between kinetic diameters of $\mathrm{CO}_{2}(3.3 \AA)$ and $\mathrm{CH}_{4}(3.8 \AA)$ molecules renders separation of one component by a simple size effect. Therefore, the material should be capable of a significant degree of $\mathrm{CO}_{2}$ adsorption, but must not allow the penetration of $\mathrm{CO}_{2}$ into the bulk, which lead to physical and chemical modification of the material. On the other hand, the produced membrane is expected to be able to control the sorption capacity of other gases like $\mathrm{N}_{2}, \mathrm{CH}_{4}$, and $\mathrm{H}_{2}$. Resistance to be poisoned by other possible contaminant gases, such as $\mathrm{H}_{2} \mathrm{O}, \mathrm{SO}_{\mathrm{x}}, \mathrm{NO}_{\mathrm{x}}$, and $\mathrm{H}_{2} \mathrm{~S}$, is necessary in order to produce a membrane that can maintain its performance for extended periods.

The main purpose of this paper is to discuss prospective advanced materials for gas separation based on these properties and to encourage the development of these materials. The following classes stand out among those prospective advanced materials for membranes based gas separation applications; hybrid material, carbon membrane materials and mixed matrix-type material.

\subsection{Hybrid Membranes}

Hybrid organic-inorganic materials have been developed for the past 20 years as an interesting alternative to the conventional organic or inorganic materials. Composite materials formed by the combination of nanoscale inorganic and organic domains are attractive for the purpose of creating new materials with new or enhanced properties compared to the single organic or inorganic material. These new or enhanced properties are principally from two synthesis approaches. The first one deals with the formation of nanocomposites in which the domain size of the inorganic phase is about 100 $\mathrm{nm}$ or less, leading to enormous interfacial areas. The second case, the hybrid structure is obtained at the molecular level and produces hybrid polymers with specific properties. Although the original study was to enhance their mechanical properties, the application areas for hybrid materials have expanded considerably with current generation of materials in line of optoelectronic, ion-conduction, biology, catalysis and membranes.

Nonporous polymer membranes possess high selectivity but poor permeability. On the other hand, porous inorganic membranes give high permeability but poor selectivity. For better results, both selectivity and permeability in a membrane should be balanced. There were several studies that attempted to introduce organic affinities to a particular gas on an inorganic membrane surface. The introduction of organic functional groups sometimes contributes to the modification of the molecular 
structure of the material, which results in favorable selectivity or permeability. Among these hybrid materials, polyimide-silica materials received the most attention in gas permeation studies.

Hybrid materials in which polymers and ceramics are dispersed at a molecular level have been investigated as promising candidate for gas separation membranes. A sol-gel reaction and polymerization process are combined to synthesize the hybrid material (Okui et al., 1995). The gas permeation of porous organic/inorganic hybrid membranes was investigated via sol-gel route and its thermal stability. The functional groups, such as methyl, propyl, 3-chloropropyl, octadecyl, 3,3,3trifluoropropyl, and phenyl were introduced to study the effect of $\mathrm{CO}_{2}$ affinity to these functional groups on the resulting material permeability properties. It was found that the separation performance of the hybrid membrane improved compared to porous membranes governed by the Knudsen flow, and gas permeability was still higher than that through nonporous membranes. In addition, it was shown that these membranes were applicable at higher temperatures compared to organic membranes. SEM observation demonstrated that the thin membrane was crack-free. Nitrogen physisorption isotherms showed that the pore size was in the range of nanometers. Gas permeability through this membrane that contained the phenyl group was approximately $\left[10^{-8}\left[\mathrm{cc}(\mathrm{STP}) \mathrm{cm} /\left(\mathrm{cm}^{2} \mathrm{~s} \mathrm{~cm} \mathrm{Hg}\right)\right]\right.$ at $25^{\circ} \mathrm{C}$. The ratios of $\mathrm{O}_{2} / \mathrm{N}_{2}$ and for $\mathrm{CO}_{2} / \mathrm{N}_{2}$ were 1.5 and 6.0 , respectively, showing that the permeations were not governed by the Knudsen flow. The permeability decreased as the temperature increased. Furthermore, the specific affinity between gas molecules and surface was observed not only in the permeation data of the hybrid membranes but also in the physisorption data as well. These results suggested that the gas permeation through the hybrid membrane was governed by the surface flow mechanism. It was also reported that these functional groups were stable at high temperatures especially the phenyl group which remained intact even at $400^{\circ} \mathrm{C}$

Silica-polyimide hybrid membranes were prepared on $\gamma$-alumina coated with $\alpha$-alumina support tubes (Kusakabe et al., 1996). Polyimide acid was synthesized from dehydration condensation of PMDA and ODA, and was mixed with silica sols at various ratios. After coating the hybrid sols on a porous tube, imidization was conducted at $350^{\circ} \mathrm{C}$ to form a defect-free thin silica-polyimide microcomposite membrane. The permeability of gases increased with increasing temperature and, therefore, the permeation of hybrid membranes was governed by the dissolution-diffusion mechanism through the polymeric zone in the membrane (See Figure 3). Carbon dioxide permeability decreased with increasing permeation temperature of a hybrid membrane with silica content of $81 \%$. Surface diffusion of $\mathrm{CO}_{2}$ through the silica zone contributed to the permeance of membranes with high silica contents, and was limited at high temperatures. Joly et al. [55] showed that the presence of silica

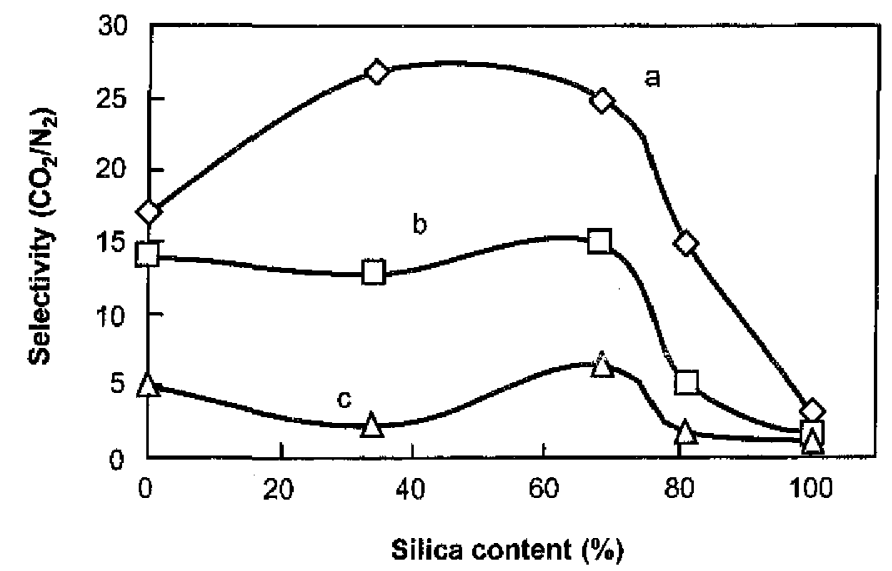

Figure 3 Effect of silica content on the selectivity of composite membrane (Kusakabe et al., 1996) 
increased the gas permeation properties in the hybrid composite membranes drastically. They prepared the polyimide-silica membranes containing $32 \%$ silica by adding TMOS to polyamic acid solution and subsequently imidizing at $300^{\circ} \mathrm{C}$. The results were analyzed in terms of the dual sorption model. In this model, it was assumed that the gas molecules dissolved in the polymer could be distributed into two distinct populations: (A) Henry type dissolution and (B) Langmuir type sorption. Higher permeability of $\mathrm{CO}_{2}(2.8 \mathrm{Barrer})$ and $\mathrm{CO}_{2} / \mathrm{N}_{2}$ selectivities $\left(\mathrm{CO}_{2} / \mathrm{N}_{2}=22\right.$ and $\left.\mathrm{CO}_{2} / \mathrm{CH}_{4}=14\right)$ were discovered the hybrid membrane compared to those of polyimide membrane (1.8 Barrer; $\mathrm{CO}_{2} / \mathrm{N}_{2}=$ 18 and $\mathrm{CO}_{2} / \mathrm{CH}_{4}=18$ ). The differences in gas permeation between the hybrid and the polyimide membrane indicated an increase in the sorption ability associated with an increase contributed by Henry's type dissolution. They also concluded, based on membrane characterization using XRD and electron micrograph, that the addition of TMOS to the polyamic acid induced the imidization rate changes and modified some morphological of the polymer matrix along with the formation of a heterogeneous material.

In a different study, Joly et al. [56] investigated the effect of the permeation temperature and silicon content on the gas transport properties of the hybrid composite membranes. They observed a considerable increase in the $\mathrm{CO}_{2}$ permeance with an increase in the silica content due to its high solubility in the composite material. They also reported that the permeability activation energies decreased when the silica content of the hybrid membranes increased. Increases in permeabilities as well as in temperature were observed, as selectivities $\left(\mathrm{CO}_{2} / \mathrm{N}_{2}\right.$ and $\left.\mathrm{CO}_{2} / \mathrm{CH}_{4}\right)$ decreased considerably at higher temperatures.

Kim and Lee [57] studied the gas transport properties of organic-inorganic hybrids of poly (amide6-b-ethylene oxide) (PEBAX). They also prepared silica via in situ polymerization of tetraethoxysilane (TEOS) by the sol-gel process. The solid-state ${ }^{29} \mathrm{Si}$ NMR, Fourier transform infrared (FT-IR), dynamic light scattering (DLS) and field emission scanning electron microphotography (FE-SEM) were used to characterize the nanodispersed inorganic network produced in the organic matrix. The wide angle $\mathrm{X}$-ray diffraction and differential scanning calorimetry technique showed that the incorporation of silica induced the structural modification of polymer chains. Gas permeation of $\mathrm{He}, \mathrm{CO}_{2}, \mathrm{O}_{2}$ and $\mathrm{N}_{2}$ were measured at various temperatures. They also added that the hybrid membranes exhibited higher gas permeability coefficients and selectivities than the PEBAX alone, particularly at elevated temperatures (see Figure 4). Activation energy of $\mathrm{CO}_{2}$ permeation through the hybrid membranes decreased due to the large contribution of heat of sorption while that of $\mathrm{N}_{2}$ increased resulting from

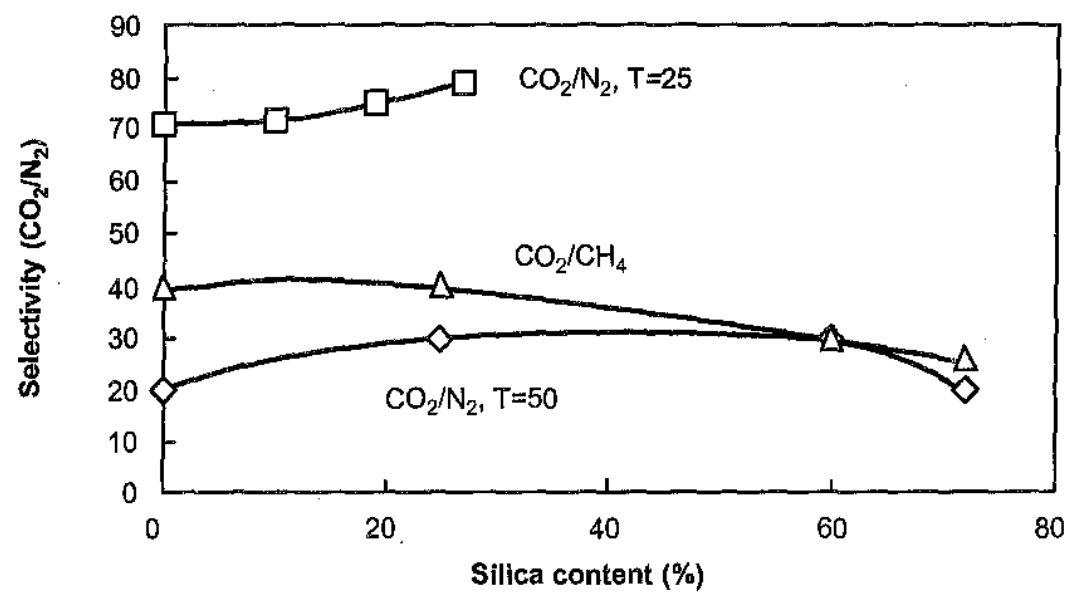

Figure 4 Effect of silica content on the selectivity $\mathrm{CO}_{2} / \mathrm{CH}_{4}$ and $\mathrm{CO}_{2} / \mathrm{N}_{2}$ of composite membrane [57] 
the increase of tortuosity and restricted chain mobility. Therefore, they concluded that high permeability and selectivity increases of the hybrid membranes were ascribed to the strong interaction between $\mathrm{CO}_{2}$ molecules and the residual hydroxyl groups on the silica domain, as well as the additional sorption sites in polyamide block of PEBAX, and the organic/inorganic interface.

Hybrid composite gas-separation membranes were prepared by Smaihi et al. [58] using a microporous polyacrylonitrile substrate and a thin organic-inorganic sol-gel layer as the selective coating. The thin sol-gel layers were obtained from co-hydrolysis of an organoalkoxysilanediphenyldimethoxysilane or phenyl trimethoxysilane and TMOS. Based on several analytical techniques (SAXS, solid-state NMR, and DSC), these hybrid networks were found to be homogeneous at the molecular level. $\mathrm{CO}_{2}$ permeation in the DPMOS-TMOS membrane increased with increasing organoalkoxide molar ratio (DPMOS or PTMOS/(DPMOS or PTMOS + TMOS)), but decreased in the PTMOS-TMOS membrane as shown in Figures 5(a) and (b). The $\mathrm{CO}_{2}$ permeation in DPMOSTMOS increased proportionally to the phenyl group concentration of the membrane material. The decrease in $\mathrm{CO}_{2}$ or $\mathrm{N}_{2}$ permeation in PTMOS-TMOS membranes was attributed to the increase in connectivity of the network with the molar composition in these membranes. The transport of $\mathrm{CO}_{2}$ through these hybrid membranes occurred due to the surface diffusion mechanism. The highest selectivity of $\mathrm{CO}_{2} / \mathrm{N}_{2}$ was observed with PTMOS-TMOS at molar composition of $81 \%$ and this occurred because of the enhanced chemical affinity between $\mathrm{CO}_{2}$ and the membrane structure, caused by an increased content of phenyl groups in the material.

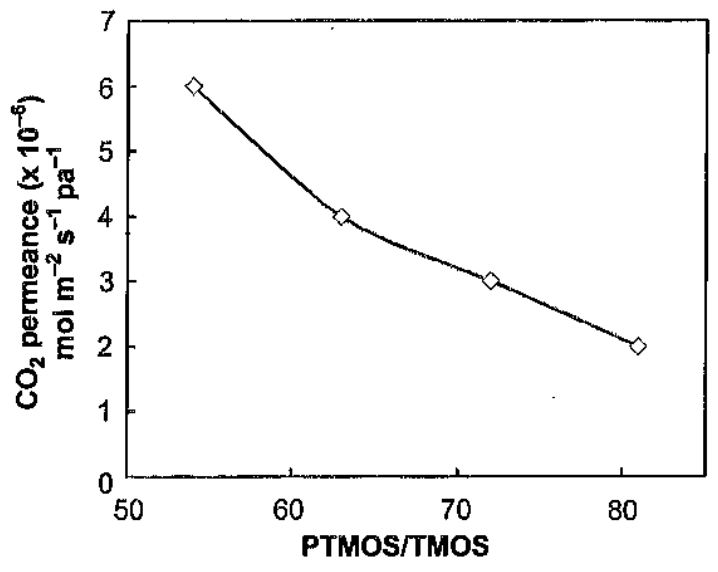

(a)

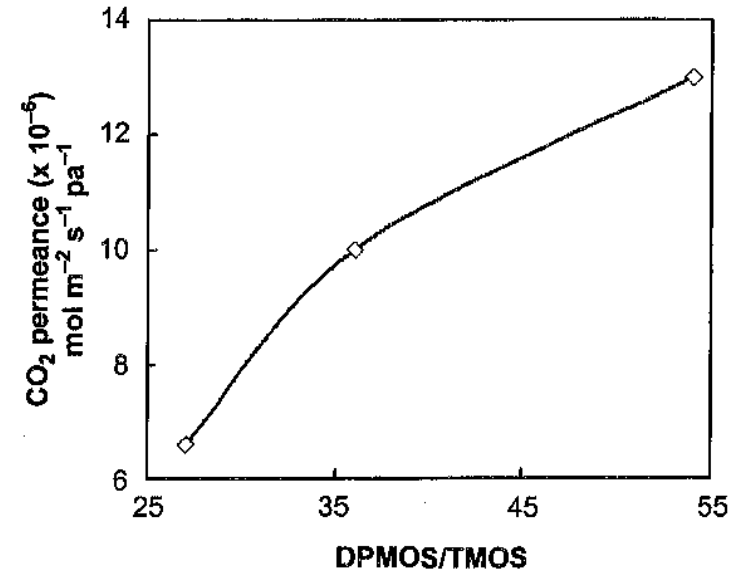

(b)

Figure 5 Permeation through hybrid membrane as a function of the organoalkoxide molar proportion [58]

Novalk [59] had prepared hybrid nanocomposite material mixing organic glass and organic polymer. The sol-gel process, with its associated mild conditions, offers a new approach to the synthesis of composite materials with domain size approaching the molecular level. They used dissolving technique to transform the polymer into sol-gel precursor solution and then leave the tetra alkyl orthosilicates to hydrolyze and to condense from glassy $\mathrm{SiO}_{2}$ phases to produce organic-inorganic composites. Depending on factors such as the structures of the organic and inorganic components, the phase morphology, the degree of interpenetration, and the presence of covalent bonds between the phases, the properties of these composites could vary greatly ranging from elastomeric rubbers to highmodulus materials. 
In other publication, Smaihi et al. (1999) studied the hybrid polyimide-siloxane copolymers containing different proportion of silica. The hybrid membranes were prepared by polycondensation, imidisation and sol-gel process composed of PMDA, aminoalkoxysilane, and TMOS. They used two coupling agent; aminopropyltrimethoxysilane (APrTMOS), and aminopropylmethyldiethoxysilane (APrMDEOS) to provide a bonding between the inorganic and the organic phase. From the infrared spectrometry and ${ }^{29} \mathrm{Si} \mathrm{NMR}$, they discovered the methyl side-groups that were linked to the silicon of APrMDEOS precursors inhibited the formation of $\mathrm{OH}$ free in the material. The gas permeation measurements were conducted at various operating temperatures for hydrogen, carbon dioxide and nitrogen. The permeability properties of the two materials varied with the siloxane content and the nature of the aminosiloxane. Thus, the presence of methyl side-groups in the APrMDEOS materials and the network crosslinking were the limiting factors for the gas permeation. The gas transport was thermally activated and the activation energy values varied with the siloxane content of the material. In addition, the permeability of $\mathrm{CO}_{2}$ decreased with increasing siloxane content, particularly, in APrMDEOS materials.

Cornelius and Marand [60] studied the hybrid inorganic-organic composites polyimides and silica structures for separating several gases including $\mathrm{CO}_{2}, \mathrm{~N}_{2}$, and $\mathrm{CH}_{4}$. These hybrid membranes that were made of FDA-6FpDA and 6FDA-6FpDA-DABA poyimides and various alkoxysilanes, were prepared by sol-gel reactions of various alkoxysilanes in the presence of fully imidized polyimides, whose chain ends and backbone functioned to different degrees of triethoxysilane groups. These hybrid membranes were then annealed at $400^{\circ} \mathrm{C}$ to drive the sol-gel reactions to a greater extent. In general, the annealing process is able to increase the gas permeation of the hybrid membranes by about 200 to $500 \%$, while the selectivity decreases slightly. The gas transport properties of these hybrid membranes were depending on the type of alkoxide employed and the final morphology of the hybrid composite. Systems with low degree of cross-linking between the inorganic and polymer components exhibited membrane performance below the upper bound. However, simultaneous improvements in selectivity and permeability were observed in the hybrid materials with favorable interactions between inorganic and polymer domains as documented by changes in viscoelastic properties. These improved interactions most likely led to the formation of an interphase consisting of constrained polymer segments that were partially incorporated into the silicate structure.

Soufyani et al. [61] studied the silicone modified silica membrane for gas separation. A typical modification was made on the thin film using hybrid material prepared from $\mathrm{TiO}_{2}-\mathrm{SiO}_{2}$ and silicone (poly-dimethyl-siloxane) by the sol-gel technique. Gas flows were measured using $\mathrm{C}_{3} \mathrm{H}_{8}, \mathrm{~N}_{2}, \mathrm{He}$ and $\mathrm{CO}_{2}$ gases. The SEM images showed a formation of rather homogeneous spheres of mean diameter of about $1 \mu \mathrm{m}$ that deposited on the thin film. These spheres supported top thin 'silicone layer' when the aging time $\left(t_{\mathrm{ag}}\right)$ was under 20 hours but there was no top thin film when $t_{\mathrm{ag}}$ was higher than 24 hours. The authors concluded that the aging time $\left(t_{\mathrm{ag}}\right)$ of the initial solution was an important parameter for the elaboration of very efficient hybrid $\mathrm{TiO}_{2}-\mathrm{SiO}_{2}$-silicone membranes.

Hu et al. [62] fabricated nano-composite membranes based on a fluorinated poly (amide-imide) and $\mathrm{TiO}_{2}$ using sol-gel method. They reported that significant improvement in selectivities of the poly (amide-imide) membrane could be observed if $\mathrm{TiO}_{2}$ was incorporated into the polymer matrix. The nano-composite membrane has a more rigid or denser structure than the corresponding pure $6 \mathrm{FPAI}$ membrane. The authors observed a specific interaction between the polar $\mathrm{CO}_{2}$ molecules and the residual $\mathrm{OH}$ groups on the $\mathrm{TiO}_{2}$ domain of the nano-composite membrane. They discovered higher selectivities of $\mathrm{CO}_{2} / \mathrm{N}_{2}$ and $\mathrm{CO}_{2} / \mathrm{CH}_{4}$ systems even for the composite membrane containing very low concentration of $\mathrm{TiO}_{2}$.

Moadebb and Koros [63] studied the effect of silica particle on the gas transport properties of the thin film of polymer. They produced thin films with six high performance polymers on silica impregnated Anapore alumina substrates. Six polymers applied in the composite membranes were: poly(hexafluorodianhydride isopropylidenedianiline) (6FDA-IPDA), poly (6FDA methylenedianiline) 
(6FDA-MDA), poly(6FDA 4,4'hexafluoro diamine) (6FDA-6FpDA), poly(6FDA 3,3'-hexafluoro diamine) (6FDA-6FmDA), tetramethyl hexafluoropolysulfone (TMHFPSF), and bisphenol-A polycarbonate (PC). They reported that a unique environment allowed intimate contact between the polymer and the silica particles. The presence of silica improved the gas separation properties of the selective layer, particularly for oxygen and nitrogen. The increase in $\mathrm{O}_{2} / \mathrm{N}_{2}$ selectivity for some membranes was accompanied by an increase in oxygen permeability. The oxygen/nitrogen separation properties of the polymers in the presence of silica fell above the so-called "upper limit" of polymeric material performance as reported for polymeric materials. In addition, the significant increase in glass transition temperature suggests that the restriction of chain segmental mobility is probably due to the adsorption of polymer to silica surface. The authors suggested that the increase in the activation energy of permeation points and the increase in energetics of diffusion were the reasons for the improvement in selective permeation.

\subsection{Carbon Membranes}

Carbon molecular sieving membranes are chemically robust materials with customized gas transport properties for gas separations. Although the concept of carbon membrane for gas separation was found in the early 1970, the interest in carbon membrane emerged after Koresh and Soffer had successfully prepared apparently crack-free molecular sieving hollow fiber carbon membranes [64]. At present, researchers have used different polymeric materials; including polyimides, to prepare carbon membranes using pyrolysis method. The attention has been focusing on materials that exhibit molecular sieving properties, such as silica, zeolite and carbon [65], which appear to be promising in gas separation. In general, carbon membranes can be divided into four major configurations that are: flat sheet, membrane supported on tube, capillary, and hollow fiber. Carbon membranes offer a number of advantages over polymeric membranes especially in terms of selectivity (above the Robeson Upper Bound) as well as thermal and chemical stability (see Figure 6). The predominant mass transfer of gas through a carbon membrane as molecular sieving is shown in Figure 7.

The carbon membranes contain constriction in the carbon matrix which approaches the molecular dimensions of the absorbing species [66]. In this manner, they are able to separate the gas molecules with similar dimension effectively. According to this mechanism, the separation is caused by the passage of smaller molecules of a gas mixture through the pores while the larger molecules are obstructed. It exhibits high selectivity and permeability for the smaller component of a gas mixture. The carbon matrix is assumed to be impervious, and permeation through carbon membranes is attributed entirely to the pore system. The pore system consists of relatively wide openings with narrow constrictions. The openings contribute the major part of the pore volume and thus responsible for the adsorption capacity, while the constrictions are responsible for the stereoselectivity of pore penetration by host molecules and for the kinetics of penetration. Hence, the diffusivity of gases in carbon molecular sieve changes abruptly depending on size and shape of molecules because the carbon molecular sieve has pore size close to the dimension of gas molecules.

Carbon molecular sieves are porous solids that contain constricted apertures that approach the molecular dimension of diffusing gas molecules. At these constrictions the interaction energy between the gas molecule and the carbon is comprised of both dispersive and repulsive interactions. When the opening becomes sufficiently small relative to the size of the diffusing molecule, the repulsive forces dominate and the molecule requires activation energy to pass through the constrictions. In this region of activated diffusion, molecules with only slight differences in size can be effectively separated through this molecular sieving. Thus, the mechanism of gas permeation and uptake through porous solids is closely related to the internal surface area and dimensions of the pores and to the surface properties of the solid, rather than to the bulk properties of the solid as in this case with 


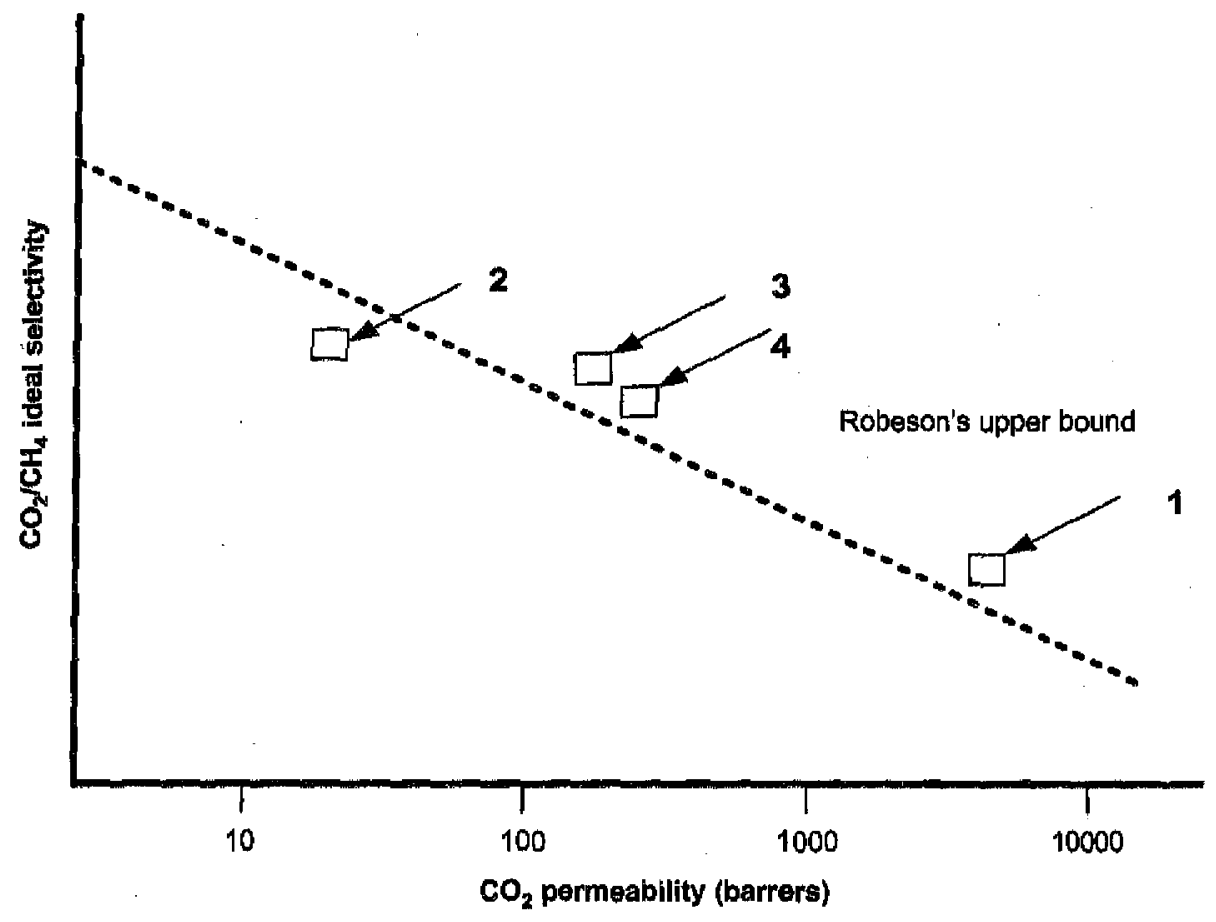

Figure 6 Transport properties of carbon membrane with upper bound (1 Shao et al, 2005; 2 Vu et al., 2003; $3 \mathrm{Kim}$ et al., 2001 and 4 Tin et al, 2004)

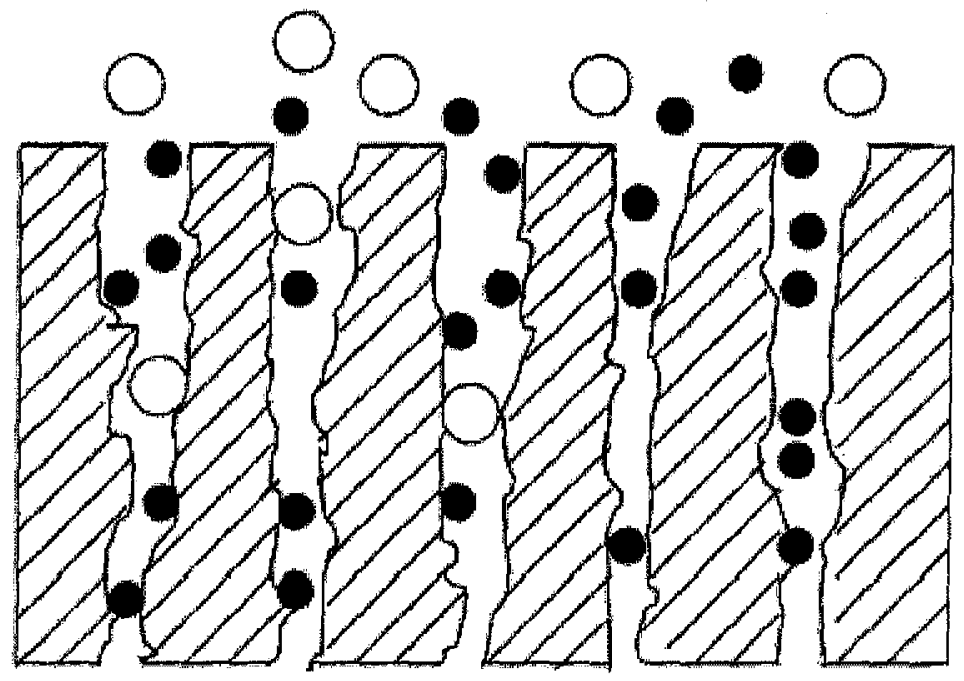

Figure 7 Typical molecular sieving transport mechanism

polymers. Molecular sieve carbon membranes that are suitable for gas separations can be prepared by pyrolyzing thermosetting polymers. Carbon molecular sieve membranes with pore diameters of 3 to $5 \AA$ have an ideal separation factor for each of various combinations of gases ranging from 4 to more than 170 . The ideal separation factors for $\mathrm{N}_{2} / \mathrm{SF}_{6}$ and $\mathrm{He} / \mathrm{CO}_{2}$ are 4 . Each factor for $\mathrm{He} / \mathrm{O}_{2}$, 
$\mathrm{He} / \mathrm{N}_{2}$ and $\mathrm{He} / \mathrm{SF}_{6}$ separation are within the range of 20-40. Meanwhile, ideal separation factor for $\mathrm{O}_{2} / \mathrm{N}_{2}, \mathrm{H}_{2} / \mathrm{N}_{2}$ and $\mathrm{O}_{2} / \mathrm{SF}_{6}$ are 8,10-20 and more than 170 , respectively [8]. The permeation characteristics of the molecular sieve carbon membrane can be varied by changing the high temperature treatment parameters [67].

Linkov et al. [68] investigated the asymmetric hollow fiber carbon membranes from the carbonization of polyacrylonitrile based precursors containing high quantity of polymers, such as polyethylene glycol and polyvinylpyrrolidone, which gave low-carbon residue upon pyrolysis. The interaction between molecules of the two polymers provided the partial miscibility condition of these polymers that occurred only in PVP precursors available. Rao and Sircar [69] reported the performance of a novel carbon membrane for separation of gas mixture containing $\mathrm{H}_{2}$ and $\mathrm{C}_{1}-\mathrm{C}_{4}$ hydrocarbon. The effect of feed pressure and the flow rate of sweeping gas were investigated. The atomic force microscopy analysis indicated that the membranes contained very narrow distribution of pore sizes. Sedigh et al. [70] fabricated the carbon membrane through pyrolysis of polyetherimide polymeric precursor. From scanning electron microscopy and energy dispersive spectroscopy, it was shown that the preparation conditions determined the carbon layer. Micropore analysis of the membrane, whose performance had degraded, indicated that the volume of pores was between $(3.6-6) \times 10^{-10} \mathrm{~m}^{3}$ had drastically decreased from the corresponding value of the as-prepared membranes.

Strano and Foley [71] had developed a new technique to synthesize carbon membranes. They synthesized defect-free carbon film on macroporous stainless-steel support. The ideal gas selectivities for the catalytic membranes were similar to those of inert nonporous carbon membranes with $\mathrm{He}$ / $\mathrm{N}_{2}=58.6$ and $\mathrm{O}_{2} / \mathrm{N}_{2}=4.9$. They applied hydrogenation of monoolefin to probe the shape selective catalytic properties and the transport selectivities of the membranes. Gilron and Soffer [71] studied the transport phenomena in microporous carbon membranes. The Knudsen diffusion occurred in the carbon membranes with molecules smaller than $0.43 \mathrm{~nm}$. They showed that the pore matrix model could be used to explain the trend of permeance change with temperature and molecular dimension. A good agreement was obtained between theoretical predictions and experimental data for gas permeance. They also discovered that the heat of adsorption followed the order of $\mathrm{H}_{2}<\mathrm{N}_{2}<\mathrm{CH}_{4}<<\mathrm{CO}_{2}$, which were consistent with the results for adsorption isotherms on bulk molecular sieve carbon.

Steel and Koros (2003) investigated the effect of porosity of carbon material and related effect on characteristics of gas separation. The carbon material was formed via the pyrolysis of polyimide precursors at several pyrolysis temperatures to alter the carbon structure. They observed that the separation properties were affected by the final pyrolysis of carbon molecular sieving material. In addition, they proposed that the ultramicropore was an important factor for molecular sieving. As for Kim et al. [67] carbon membranes were produced from pyrolysis of polyimide-polyvynilpyrrolidone (PVP) blend in order to study the effect of thermal pyrolysis on the gas separation properties. They approved that the structure of carbon molecular membranes was affected by thermal properties of polymers. Both gas permeability and selectivity of the carbon membranes prepared from polyimidepolyvinylpyrrolidone blends increased as PVP was increased and decreased as the final pyrolysis temperature increased. This was attributed to the pyrolysis temperature which caused the blocking of the diffusional pathway of gas molecules on the carbon membranes. They also reported that the carbon membranes prepared by incorporating PVP showed a 28\% increase in gas permeability for $\mathrm{O}_{2}$.

Zhang et al. [72] had introduced nanoseeds for the regrowth of zeolites in the porous carbon using a seeding technique in the seed ethanol solution. The composite-zeolite membranes have potential applications in gas separation. The SEM and XRD, displayed the highly grown zeolite $\mathrm{NaA}$-carbon composite membranes on the seeded porous supports. A polyimide matrimid 5218 was used as a precursor for carbon molecular sieve membranes by Tin et al. [73]. They studied the effect 
of chemically modified and treatment of solvent polyimide. They modified the carbon membrane using chemical cross-linking matrimid 5218 by immersing the membrane in a $10-\mathrm{w} / \mathrm{v} \%$ of p-xylenediamine methanol solution. They used a constant volume to determine the permeability of pure gas. They reported that the gas permeabilities through the carbon membranes decreased in the order of increasing gas kinetic diameters as in $\mathrm{CO}_{2}>\mathrm{O}_{2}>\mathrm{N}_{2}>\mathrm{CH}_{4}$. They also observed that the permeability of carbon membranes derived from cross-linked matrimid decreased with cross-linking density while the maximum selectivity was obtained for carbon membrane of 1-day cross linked matrimid. The results suggested that the selectivity increased at a low cross-linking density and vice versa. They concluded that the swelling of polymer chains occurred during cross-linking at a low cross-linking density, therefore the selectivity increased at that condition. They added that the swelling using methanol was an effective chemical modification in fabrication of carbon membranes.

In another study [74], they used P84 (BTDA-TDI/MDI, copolyimide of 3,3' 4,4' -benzophenone tetracarboxylic dianhydride and $80 \%$ methylphenylene-diamine $+20 \%$ methylene diamine) as a precursor in preparing carbon membranes to study the separation of $\mathrm{CO}_{2} / \mathrm{CH}_{4}$. The pyrolysis process was carried out at $550-800^{\circ} \mathrm{C}$. They reported that the highest selectivity was obtained from a carbon pyrolyzed at $800^{\circ} \mathrm{C}$. Hence, the pyrolysis temperature proved to affect the permeation properties of carbon membranes significantly. Park et al. [75] had produced carbon membranes containing silica according to predetermined pyrolysis step using imide-siloxane copolymers (PISs) that was synthesized from benzophenone tetracarboxylic dianhydrides (BTDA), 4,4' -oxydianiline (ODA), and amine-terminated polydimethylsiloxane (PDMS). They used a random segmented copolymer and a block segmented copolymer to form different morphology at the same chemical composition. They found that the membrane derived from a random copolymer had a micro-structure containing a small well-dispersed silica domain. Therefore, they concluded that the gas transport through the membrane was affected by the morphology of the polymeric precursor.

Shao et al. [76] studied the effect of casting solvent on morphologies and separation factors of carbon membranes derived from 6FDA/PMDA-TMMDA. They found that the films that were cast from $\mathrm{CH}_{2} \mathrm{Cl}_{2}$ or NMP showed amorphous morphology while the film from DMF had crystalline structures. They also observed that the gas separation performances of different morphologies were significantly different. Moreover, they reported that the pyrolysis temperature affected the gas separation performance strongly. However, the selectivity increased at higher pyrolysis temperature while the permeability decreased. Barsema et al. [77] investigated the intermediate structure of polymer and effect on the gas separation properties. They used polyimide matrimid 5218 to make the carbon molecular membranes. They reported that below $425^{\circ} \mathrm{C}$ no thermal decomposition ocurred. They discovered that the structure of carbon membranes became denser at treatments below the $\mathrm{Tg}$ of the polymer, whereas above the $\mathrm{Tg}$ a concurrent formation of charge transfer complexes took place. They also found that the permeability increased at heat treatment above $475^{\circ} \mathrm{C}$ caused by thermal decomposition and transition process on carbon membranes. They also found that heat treatment at a temperature of $475^{\circ} \mathrm{C}$ resulted in good resistance to plasticization and exhibited sustained permeation rates compared to untreated membranes.

Lagorsse et al. [78] reported a novel method to produce carbon molecular membrane modules. They used honeycomb configuration to improve the modules. The advantages of the honeycomb modules compared to the conventional modules are the high packing density and thermochemical stability. They observed that the new module of membranes gave high permeability and selectivity. It was clear from the above discussion that carbon membranes have great potential to replace other inorganic membranes in the market though there is still room for improvement before they can become commercialized membranes for gas separation. However, carbon membranes have many useful characteristics and are able to separate gas mixtures that have similar size of gas molecules efficiently. 


\subsection{Mixed Matrix Membranes}

Significant improvements in the performance of polymeric gas separation membranes have been witnessed for the past two decades. Modifications in the physical and chemical structures of polymer films have been carried out to achieve better separation characteristics. The membrane structure may determine the separation mechanism and the applications. Besides that, the membrane morphology is one of the most important parameters that affect the performance of membrane. On the other hand, molecular sieving materials like zeolites and carbon molecular sieves (CMS) offer attractive transport properties, but difficult and expensive to be processed as membranes [79]. Therefore, interest has been focusing on novel-zeolite or carbon filled mixed matrix membranes because of the interactions of materials in the membrane matrix that favor selective separations.

Mixed matrix materials that are comprised of molecular sieve domains embedded in processable polymer matrices have the potential to produce cost effective as well as high-performance gas separations membrane. Mixed matrix membranes are a new class of membrane materials that offer the potential of advancing the current technology significantly. This concept involves the incorporation of highly selective molecular sieves within a polymeric matrix, resulting in a hybrid membrane material with superior selectivity over that of polymer matrix alone, while maintaining processability under current membrane formation technology. The resulting mixed matrix membranes (MMM) may have the advantages of both materials: the processability of polymers and the superior gas transport properties of molecular sieves. However, their performance suffers from defects caused by poor contact at the molecular sieve/polymer interface. The molecular sieving material can be a zeolite or CMS. Figure 8 illustrates the schematic of a mixed matrix membrane. A careful matching of the intrinsic permeability and selectivity of the support matrix and the molecular sieve domain is a necessary [79]. Composite organic-inorganic membranes have become an expanding field of research as the introductions of inorganic molecules are able to improve the characteristics of a matrix.

Zeolite-filled rubbery polymer membranes were first investigated by Jia $e t$ al. [80]. They studied the effect of silica in the composite membranes, consisted of a highly hydrophobic zeolite, silicalite-1, and PDMS polymer on the permeation properties. They observed that the permeabilities of $\mathrm{He}, \mathrm{H}_{2}, \mathrm{O}_{2}$ and $\mathrm{CO}_{2}$ increased with increasing silicalite-1, while that of $\mathrm{N}_{2}, \mathrm{CH}_{4}$ and $\mathrm{C}_{4} \mathrm{H}_{10}$ decreased. It was concluded that the silicalite played the role of molecular sieve in the membrane by facilitating the permeation of smaller molecules but hindering the permeation of larger ones, although

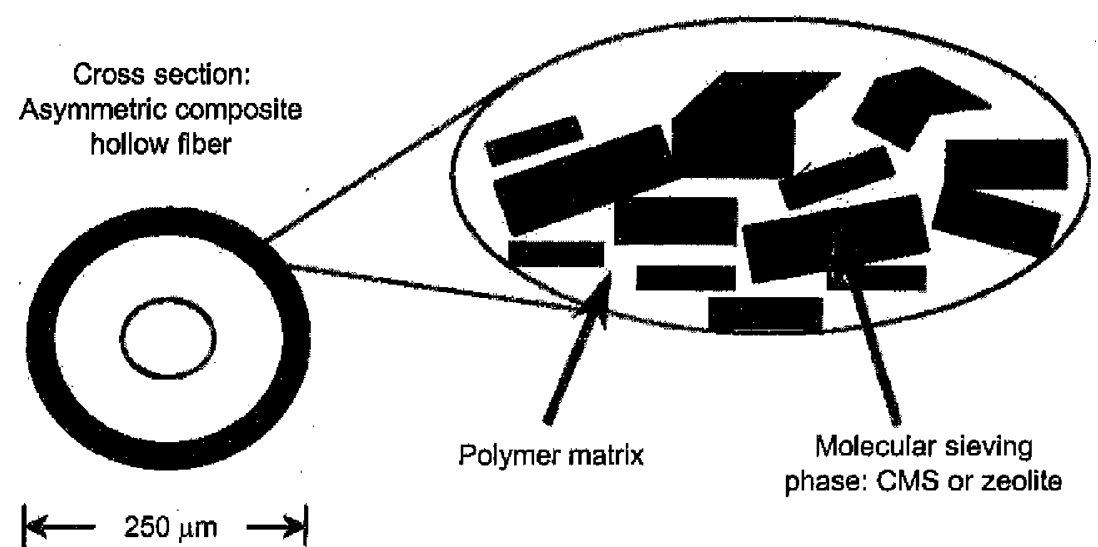

Figure 8 Schematic of a mixed matrix membrane 
the pore openings were larger than the size of the permeating gases. They reported that the membrane type affected the distinct gas permeation. A new parameter, the facilitation ratio of zeolite, assisted in characterizing the function of silicalite in the menbrane. By this parameter it was confirmed that silicalite played an important role in the molecular transport and the altered permeabilities and selectivities were the results of a molecular sieving effect of the silicalite. Permeabilities of $\mathrm{CO}_{2}$ increased, while the permeabilities of $\mathrm{N}_{2}$ and $\mathrm{CH}_{4}$ decreased with increased silicalite content in the composite membrane. The best selectivities for $\mathrm{CO}_{2} / \mathrm{N}_{2}$ and $\mathrm{CO}_{2} / \mathrm{CH}_{4}$ for composite membrane containing $70 \%$ silica were 17 and 9 , respectively, at $30^{\circ} \mathrm{C}$ with the $\mathrm{CO}_{2}$ permeability of 3835 Barrer.

Polymer-zeolite mixed matrix membranes were also prepared by Süer et al. [81]. They studied the effect of zeolite loading in the permeation rates of $\mathrm{N}_{2}, \mathrm{O}_{2}, \mathrm{Ar}, \mathrm{CO}_{2}$ and $\mathrm{H}_{2}$. They observed that the permeability decreased up to a loading of $8 \%$ for zeolite $13 \mathrm{X}$, and $25 \%$ for zeolite $4 \mathrm{~A}$ before it increased for higher zeolite loadings. It was concluded that the channel network matured as the zeolite loading increased in the matrix, and consequently connected the separated voids that provided an additional route for gas molecules. Typically, this led to an increase in the permeation of all gases with increasing zeolite content in the mixed matrix membranes. The polarity and adsorption of gases within the membrane matrix in addition to shape-selective properties of the zeolite were attributed to the transport of gases across the zeolite mixed matrix membranes. $\mathrm{CO}_{2}$ molecules have the ability to interact with the polar surface of zeolite $13 \mathrm{X}$ and $4 \mathrm{~A}$ during permeation. Hence, $\mathrm{CO}_{2}$ permeability and selectivity increased considerably with increasing zeolite loadings in the mixed matrix membranes. The permeation properties of the membrane also depend on the type of zeolite in the matrix. Duval et al. [82] focused their study on the effect of incorporation of zeolite particle into glassy polymer membranes for gas separation properties. When silicalite-1 was added into glassy polymers such as cellulose acetate (CA), polysulfone (PS), polyetherimide (PEI) and polyimide (PI), permeabilities increased but selectivities decreased or maintained. This was caused by void formation. Therefore, they also investigated various methods to improve the internal membrane structure such as surface modification of the external surface of zeolite with silane, preparation above the glass-transition temperature, and heat treatment. However, the $\mathrm{CO}_{2} / \mathrm{CH}_{4}$ selectivities of membranes were hardly improved. Gür [83] approached this problem with another method. Zeolite 13X filled PSF membranes were fabricated by a melt extrusion process, and then $\mathrm{CO}_{2}, \mathrm{O}_{2}, \mathrm{~N}_{2}$ and $\mathrm{CH}_{4}$ permeabilities of the membranes were measured. However, the pronounced effect of the filler was not observed. He concluded that the pore size of zeolite $13 \mathrm{X}$ was larger than the kinetic diameters of any gas molecules tested. Hence, separation due to size exclusion did not take place.

Yong et al. [84] synthesized polyimide membranes filled with zeolites by introducing $2,4,6-$ triaminopyrimidine (TAP). They reported that TAP could enhance the contact of zeolite particles with polyimide chains by forming hydrogen bonding between them. The addition of TAP to PI/ zeolite membrane increased the gas selectivities significantly at the expense of the gas permeabilities. They reported that higher gas permeabilities were exhibited by PI/zeolite 13X/TAP membrane with lower selectivities, compared to PI/TAP membranes having the same PI/TAP ratio; they observed lower gas permeabilities but higher selectivities with the PI/zeolite 4A/TAP membrane. Therefore, they concluded that the molecular sieving effect of zeolites took place when the kinetic diameter of the penetrant gas approached the pore size of the zeolites.

Gulsen et al. [85] synthesized mixed matrix composite membranes from polypyrrole (PPy) and polybisphenol-A-carbonate (PC) by a combined in-situ polymerization and solvent evaporation method. The rationale for preparing composite membranes was to have a combination of good transport properties of conductive polymer, PPy, and good mechanical properties of insulating polymer, PC. It was found that the supporting electrolyte and its concentration were the most effective parameters for membrane performance. The best results were obtained when the membrane was dried at $100^{\circ} \mathrm{C}$ and cast from an initial solution of $7 \% \mathrm{PC}$ containing $0.01 \mathrm{M}$ para-toluene sulfonic acid as support electrolyte. Selectivities values of these membranes were $\mathrm{CO}_{2} / \mathrm{N}_{2}$ of $5.9, \mathrm{CO}_{2} / \mathrm{CH}_{4}$ of 
3.1 while $\mathrm{CO}_{2}$ permeability was 11.6 Barrer. Tantekin-Ersolmaz et al. [86] investigated the effect of zeolite particle size on the performance of silicalite-PDMS mixed matrix membranes at two different zeolite loadings. The permeabilities of the silicalite-PDMS mixed matrix membranes increased with increasing particle size of zeolite. Furthermore, they reported that the effect of particle size of zeolite was more obvious at higher zeolite loading.

In a further study Tantekin-Ersolmaz et al. [87] conducted a research on the effect of zeolite loading on the zeolite-PDMS mixed matrix membranes to separate n-pentane from i-pentane. They used HZSM-5, NaZSM-5, 4A and 5A as zeolite fillers. They observed no significant improvement on the separation performance compared to the original polymer membrane. They also discovered that the interactions occurred in the zeolite-polymer interface and played a significant role in the zeolite-filled PDMS membranes. Pechar et al. [88] fabricated a glassy fluorinated polyimide zeolitemixed matrix membrane. They used 6FDA-6FpDA-DABA, a glassy polyimide as a polymer matrix and modified zeolite (ZSM-2) as filler. From SEM and TEM, they found no voids between the polymer and the zeolite.

Vu et al. [89] studied the effect of carbon molecular sieves that were incorporated into matrimid 5218 and ultem 1000 to form mixed matrix membrane for gas separation. The matrimid and ultem mixed matrix showed a significant enhancement in both $\mathrm{CO}_{2} / \mathrm{CH}_{4}$ and $\mathrm{O}_{2} / \mathrm{N}_{2}$ selectivities by as much as $45 \%$ in $\mathrm{CO}_{2} / \mathrm{CH}_{4}$ selectivity and $20 \%$ in $\mathrm{O}_{2} / \mathrm{N}_{2}$ selectivity. They concluded that the incorporation of molecular sieves or zeolite into mixed matrix membrane led to several advantages. The carbon molecular sieves particles have better affinity than glassy polymers, thus causing good adhesion and better polymer-sieve contact, which make the film formation easier. Apart from that, the permeation properties of the CMS particles can be tailored by modifying pyrolysis procedure. Therefore, mixed matrix membranes containing carbon molecular sieve is adaptable for desired gas separations. In another study by Vu et al. [90] the performance of mixed matrix membrane with the $\mathrm{CO}_{2} / \mathrm{CH}_{4}$ feed containing a vapor impurity of toluene was examined. The mixed matrix membrane was composed of carbon molecular sieve dispersed within a matrimid 5218. The result indicated that the mixed matrix membrane exhibited stability in the presence of the toluene.

Moore et al. [91] investigated the effect of water vapor on mixed matrix membranes. The experimental results showed that mixed matrix membranes that were composed of zeolite 4A dispersed in poly(vinyl acetate) were affected by water that was adsorbed into the pores of zeolite 4A. Water clearly led to swelling and concomitant increase in the oxygen permeability in poly(vinyl acetate). However, in mixed matrix membranes the SSZ-13 sieves appeared to be relatively unaffected by water, which made SSZ-13 to be an ideal mixed matrix membrane candidate for an air separation. Chung et al. [92] studied the gas separation performance of a modified matrimid- $\mathrm{C}_{60}$ mixed matrix membranes. The membranes were synthesized by physically blending a series of benzylamine-modified fullerene, $\mathrm{C}_{60}$ with pure matrimid 5218 . The increase in the $\mathrm{Tg}$ indicated that the modified membrane possessed strong interfacial interaction. They reported that the selectivity for $\mathrm{He} / \mathrm{N}_{2}$ increased as the selectivity of $\mathrm{O}_{2} / \mathrm{N}_{2}$ and $\mathrm{CO}_{2} / \mathrm{CH}_{4}$ was almost constant. The gas separation properties of the polycarbonate-polypyrrole mixed matrix membrane with an introduction of conducting polymer were discussed by Hacarlioglu et al. [93]. They mentioned that the introduction of conducting polymer as filler could increase the performance of composite membrane. They also found that the membrane performances were strongly affected by membrane casting procedures.

Anson et al. [94] studied the effect of carbon loading, temperature and pressure on the performance of mixed matrix membrane for the separation of $\mathrm{CO}_{2}$ from $\mathrm{CH}_{4}$. They used acrylonitrile-butadienestryrene (ABS) as the polymer matrix and activated carbon (AC) as the inorganic fillers. The ABS$\mathrm{AC}$ mixed matrix membranes showed increases in both $\mathrm{CO}_{2}$ permeabilities and $\mathrm{CO}_{2} / \mathrm{CH}_{4}$ selectivities $(40-100 \%)$ as the \% percentage of carbon loading increased. This could be attributed to the higher in both specific surface and $\mathrm{CO}_{2}$ adsorption caused by the presence of a tight interfacial contact between the polymeric and filler phase. Jiang et al. [95] fabricated the matrimid-polyethersulfone dual layer 
hollow fiber membrane with an ultra-thin outer layer for gas separation. They discussed the effect of spinneret, coagulant temperature and dope flow rates on membrane morphology and separation performance. They found that spinneret and coagulant temperatures played important roles on duallayer membrane performance. At the optimum temperature of coagulant and spinneret of $25^{\circ} \mathrm{C}$, hollow fibers showed a better performance with $\mathrm{O}_{2} / \mathrm{N}_{2}$ selectivity of 6.26 in pure gas tests and $\mathrm{CO}_{2} /$ $\mathrm{CH}_{4}$ selectivity of 40 in mixed gas tests. Low coagulant temperatures produced membranes with much lower permeance and selectivity that was possibly because of high substructure resistance. They also reported that the elemental analyses on the inner skin of the outer layer and the outer skin of the inner layer showed higher spinneret temperatures that could enhance the inter-layer diffusion between the two polymers because of a low dope viscosity and high molecular diffusion rate.

In another research, Jiang et al. [96] studied the nano-sized zeolite distribution in mixed matrix membranes formation. They used nano sized zeolite beta to fabricate both single layer and dual layer mixed matrix hollow fiber. They observed that the shear within the spinneret, die swell when exiting from the annulus spinneret and elongation drawing in the air region played important roles in determining the nano-particle distribution in the resultant fibers. They also determined that the outer layer of hollow fiber had a defective skin for Knudsen diffusion.

\subsection{RECENT DEVELOPMENT AND FUTURE DIRECTION}

Nowadays, membrane systems process more than 4000 million cubic meters of gas annually. Membranes are used in a wide range of applications, including $\mathrm{CO}_{2}$ removal from natural gas, hydrogen recovery from ammonia purge gas and air separation [8]. During the recent years, studies on gas separation membranes have been progressing significantly. New inorganic and organic membranes that have been discussed in this paper showed good permeation properties for gas separation. Currently, the porous ceramic membranes dominate the market of commercialized inorganic membranes for gas separations. The most prevalent membrane materials are metallic oxides and to be precise are alumina and zirconia, but other materials, such as titania, carbon or glass are also available.

In general, the inorganic and organic membranes suffer from several problems at the desired operating conditions such as thermal stability, low selectivity and economic feasibility issues. As the development of current techniques continues to push the membranes closer toward commercial application, high potential innovative materials that can lead to new generations of membranes for gas separation must be considered too. Hybrid membranes are modified inorganic membranes with the organic component altering the ceramic membrane function. It is a well known fact that $\mathrm{CO}_{2}$ permeation increases when there is a chemical affinity with some molecular groups in the membrane [58]. The same phenomenon occurs for the fluoro group, phenyl group, and carbonyl group in esters and ketones. Meanwhile, the main problem in the application of hybrid membranes is the fabrication method. Therefore, much research is necessary to further develop the fabrication techniques in producing hybrid membranes.

Another material that catches the attention of researchers in the field of gas separation is carbon membrane. Carbon membranes have great potential to be applied in gas separations particularly when the gas molecules to be separated are smaller than 4.0-4.5 $\AA$. However, carbon membranes are not suitable to separate gas mixtures, such as $i$ so-butane/ $n$-butane, gas-vapour mixtures, air/ hydrocarbons and $\mathrm{H}_{2}$ /hydrocarbon. In addition, these membranes face problems like being very brittle and fragile that requires more careful handling. Therefore, carbon membranes are difficult and expensive to be fabricated [8]. The carbon membranes demonstrate the highest selectivities in most separations, but low permeability. Ismail and David [8] reported that there are only a few 
manufacturers that are involved in the production of carbon membranes. This is because of high expenses in producing and packaging of carbon membranes. Thus, these limit their usage in industrial scale. Therefore, more studies must be conducted to investigate the optimum conditions in preparing carbon membranes with the desired performance. However, the cost of carbon membrane per unit of membrane area was reported to be between one and three orders of magnitude greater than the polymeric membrane [97]. The high cost in the carbon membranes production is caused by the use of polyimide as a precursor material. Therefore, the trend of investigation must be directed to the development of a more economical material as a precursor for carbon membrane. Koros and Mahajan [98] summarized the main challenges that the current membrane technology is facing. Among them are to maintain the stability of the membrane at high temperature and corrosive feed as well as to produce higher selectivity membrane with ease in production.

For future study, the other material that is hoped to be able to solve the challenges mentioned above is mixed matrix membrane. Mixed matrix composite (MMC) materials are comprised of molecular sieving materials embedded in a polymer matrix that have the potential in producing cost effective and high performance gas separation membranes. The molecular sieving material can be zeolite, carbon molecular sieve and carbon nanotube. The unique characteristic of carbon nanotube makes it a more promising material to be applied in polymer matrix. Kashiwagi et al. [99] reported that the small fraction of carbon nanotube in polymer composite can improve the thermal degradation and increase the adsorption. Furthermore, careful matching of the intrinsic permeability and selectivity of the support matrix and the molecular sieve domains is necessary in order to improve the membrane performance.

To further expand the applications of mixed matrix materials for membrane applications, one must explore any approach to convert this unique material into useful forms, such as asymmetric flat membranes or hollow fibers. All of the above studies indicated that the adhesion between the polymer phase and the filler appeared to be a major problem in the fabrication of mixed matrix membrane. The weak polymer-filler interactions led to the tendency of the filler to form voids at the interface between the polymer and the filler. Therefore, fabrication of mixed matrix hollow fibers that were able to separate gas more efficiently appeared to be a great challenge. Thus, discovering the technique to produce a mixed matrix membranes with excellent separation properties without increasing the cost tremendously, will be a major breakthrough in this field. In addition, choosing the right polymer for producing the membrane is crucial and among the potential are polyphenylene oxide, polyanylene, blend polyimide and ketone.

It is obvious from the above discussion that mixed matrix membranes still require improvement before they can become dominant commercialized gas separation membrane. A present, mixed matrix membrane is foreseen to have great potential to replace other gas separation membranes in the market because they have a lot of useful characteristics and are able to separate gas mixtures efficiently.

\subsection{CONCLUSION}

Extensive research in the development of gas separation membranes based on materials indicates that membrane technology is growing and providing an alternative for industrial gas separation processes. The development of membrane material has become the major of research interest because it stresses on the importance of having high permeability, selectivity, thermal stability and chemical stability gas separation membranes. A competition between the three main branches of advanced material membranes which are (i) hybrid membranes (ii) carbon membranes and (iii) mixed matrix membranes can be observed. It seems that all three membrane materials will find their specific applications in gas separation processes. Therefore, research will continue in developing more effective 
processing of advanced material into large scale module, improving chemical and structural properties in order to produce higher intrinsic selectivity coupled with greater chemical and thermal stability and identifying new material with relatively low cost and more resistance to plastization - induced losses intrinsic selectivity.

\section{ACKNOWLEDGEMENTS}

The authors gratefully acknowledge the financial support from the Ministry of Science Technology and Innovation, Malaysia.

\section{REFERENCES}

[1] Klopffer, M. H. and B. Flaconnèche. 2001. Transport Properties of Gases in Polymers: Bibliographic Review. Oil \& Gas Science and Technology - Rev. IFP. 56: 223-244.

[2] Naylor, T. V. 1989. Permeation Properties. In Comprehensive Polymers Science. Oxford: Pergamon Press. 2: 643-668.

[3] Stern, S. A. 1994. Polymers for Gas Separations: The Next Decade. J. Membr. Sci. 94: 1-65.

[4] Drioli, E. and M. Romano. 2001. Progress and New Perspectives on Integrated Membrane Operations for Sustainable Industrial Growth. Ind. Eng. Chem. Res. 40: 1277-1300.

[5] Baker, R. 2002. Future Directions of Membrane Gas Separation Technology. Ind. Eng. Chem. Res. 41: 1393-1411.

[6] Caro, J., M. Noack, P. Kolsch, and R. Schafer. 2000. Zeolite Membranes - State of Their Development and Perspective. Microporous and Mesoporous Material. 38: 3-24.

[7] Lin, Y. S. 2001. Microporous and Dense Inorganic Membranes: Current Status and Prospective. Sep. and Purif. Tech. 25: 34-55.

[8] Ismail, A. F. and L. I. B. David. 2001. A Review on the Latest Development of Carbon Membranes for Gas Separation. J. Membr. Sci. 193: 1-18.

[9] Nijmeijer, A., B. J. Bladergroen, and H. Verweij. 1998. Low-temperature CVI Modification of $\gamma$-alumina Membranes. Microporous and Mesoporous Materials. 25: 179-184.

[10] Pan, M., C. Cooper, Y. S. Lin, and G. Y. Meng. 1999. CVD Modification and Vapor/Gas Separation Properties of Nanoporous Alumina Membranes. J. Memb. Sci. 158: 235-241.

[11] Ahmad, A. L., M. R. Othman, and H. Mukhtar. 2004. $\mathbf{H}_{2}$ Separation from Binary Gas Mixture using Coated Alumina-Titania Membrane by Sol-Gel Technique at High-Temperature Region. International Journal of Hydrogen Energy. 29: 817-828.

[12] Aoki, K., K. Kusakabe, and S. Morooka. 1998. Gas Permeation Properties of A-Type Zeolite Formed on Porous Substrate by Hydrothermal Synthesis. J. Membr. Sci. 141: 197-205.

[13] Hasegawa, Y., K. Watanabe, K. Kusakabe, and S. Morooka. 2001. The Separation of $\mathrm{CO}_{2}$ using Y-type Zeolite Membranes Ion-exchanged with Alkali Metal Cations. Sep. and Purif. Tech. 22-23: 319-325.

[14] Li, S., J. L. Falconer, and R. D. Noble. 2004. SAPO-34 Membranes for $\mathrm{CO}_{2} / \mathrm{CH}_{4}$ Separation. J. Membr. Sci. 241: 121-135.

[15] Giannakopoulos, I. G. and V. Nikolakis. 2005. Separation of Propylene/Propane Mixtures Using Faujasite-Type Zeolite Membranes. Ind. Eng. Chem. Res.; (Communication) . 44: 226230 .

[16] de Vos, R. M. and H. Verweij. 1998. Improved Performance of Silica Membranes for Gas Separation. J. Membr. Sci. 143: 37-51. 
[17] de Vos, R. M., W. F. Maier, and H. Verweij. 1999. Hydrophobic Silica Membranes for Gas Separation. J. Membr. Sci. 158: 277-288.

[18] Kusakabe, K., S. Sakamoto, T. Saie, and S. Morooka. 1999. Pore Structure of Silica Membranes Formed by a Sol-Gel Technique Using Tetraethoxysilane and Alkyltriethoxysilanes. Sep. Purif. Tech. 16: 139-146.

[19] Kusakabe, K., F. Shibao, G. Zhao, K.-I. Sotowa, K. Watanabe, and T. Saito. 2003. Surface Modification of Silica Membranes in a Tubular-type Module. J. Membr. Sci. 215: 321-326.

[20] Peters, T. A., J. Fontalvo, M. A. G. Vorstman, N. E. Benes, R. A. van Dam, Z. A. E. P. Vroon, E. L. J. van Soest-Vercammen, and J. T. F. Keurentjes. 2005. Hollow Fibre Microporous Silica Membranes for Gas Separation and Pervaporation: Synthesis, Performance and Stability. J. Membr. Sci. 248: 73-80.

[21] Tanioka, A, A. Obayaski, Y. Kageyama, K. Miyasaka, and K. Ishikawa. 1982. Effects of Carbon Filler on Sorption and Diffusion of Gases through Rubbery Materials. J. Poly. Sci.: Polymer Physics. 20: 2197-2208.

[22] Sada, E., H. Kumazawa, P. Xu, and H. Nishikawa. 1987. Gas Transport in Rubbery Polymers. J. Appl. Poly. Sci. 33: 3037-3044.

[23] Kamiya, Y., K. Terada, Y. Naito, and J.-S. Wang. 1995. Sorption, Diffusion, and Partial Molar Volumes of C4 Hydrocarbons in Rubbery Polymers. J. Poly. Sci. Part B: Polymer Physics. 33: 1663-1671.

[24] Ettouney, H. and U. Majeed. 1997. Permeability Functions for Pure and Mixture Gases in Silicone Rubber and Polysulfone Membranes: Dependence on Pressure and Composition. J. Membr. Sci. 135: 251-261.

[25] Merkel, T. C., R. P. Gupta, B. S. Turk, and B. D. Freeman. 2001. Mixed-Gas Permeation of Syngas Components in Poly(Dimethylsiloxane) and Poly(1-Trimethylsilyl-1-Propyne) at Elevated Temperatures. J. Membr. Sci. 191: 85-94.

[26] Orme, C. J., M. K. Harrup, T. A. Luther, R. P. Lash, K. S. Houston, D. H. Weinkauf, and F. F. Stewart. 2001. Characterization of Gas Transport in Selected Rubbery Amorphous Polyphosphazene Membranes. J. Membr. Sci. 186: 249-256.

[27] Feng, X., P. Shao, R. Y. M. Huang, G. Jiang, and R. Xian. 2002. A Study of Silicone Rubber/ Polysulfone Composite Membranes: Correlating $\mathrm{H}_{2} / \mathrm{N}_{2}$ and $\mathrm{O}_{2} / \mathrm{N}_{2}$ Selectivities. Sep. and Purif. Tech. 27: 211-223.

[28] Raptis, V. E., I. G. Economou, D. N. Theodorou, J. Petrou, and J. H. Petropoulos. 2004. Molecular Dynamics Simulation of Structure and Thermodynamic Properties of Poly (dimethylsilamethylene) and Hydrocarbon Solubility Therein: Toward the Development of Novel Membrane Materials for Hydrocarbon Separation. 37: 1102-1112.

[29] Kawakami, M., H. Iwanaga, Y. Hara, M. Iwamoto, and S. Kagawa. 1982. Gas Permeability of Cellulose Nitrate/poly(ethylene glycol) Blend Membranes. J. Appl. Poly. Sci. 27: 2387-2393.

[30] Matsumoto, K. and P. Xu. 1993. Gas Permeation Properties of Hexafluoro Aromatic Polyimides.J. Appl. Poly. Sci. 47: 1961-1972.

[31] Costello, L. M., D. R. B. Walker, and W. J. Koros. 1994. Analysis of a Thermally Stable Polypyrrolone for High Temperature Membrane-Based Gas Separations. J. Membr. Sci. 90: $117-130$.

[32] Kawakami, H., M. Mikawa, and S. Nagaoka. 1996. Gas Transport Properties in Thermally Cured Aromatic Polyimide Membranes. J. Membr. Sci. 118: 223-230.

[33] Rao, M. B. and S. Sircar. 1993. Nanoporous Carbon Membranes for Separation of Gas Mixtures by Selective Surface Flow. J. Membr. Sci. 85: 253-264.

[34] Hassan, M. H., J. D. Way, P. M. Thoen, and A. C. Dillon. 1995. Single Component and Mixed Gas Transport in a Silica Hollow Fiber Membrane. J. Membr. Sci. 104: 27-42. 
[35] Hirayama, Y., Y. Kase, N. Tanihara, Y. Sumiyama, Y. Kusuki, and K. Haraya. 1999. Permeation Properties of $\mathrm{CO}_{2}$ and $\mathrm{N}_{2}$ of Poly(ethylene oxide)-Containing and Cross-linked Polymer Films. J. Membr. Sci. 160:87-99.

[36] Liu, Y., R. Wang, and T.-S. Chung. 2001. Chemical Cross-Linking Modification of Polyimide Membranes for Gas Separation. J. Membr. Sci. 189: 231-239.

[37] Chung, T.-S., M. L. Chng, K. P. Pramoda, and Y. Xiao. 2004. PAMAM Dendrimer-Induced Cross-Linking Moditication of Polyimide Membranes. Langmuir. 20: 2966-2969.

[38] Li, J., S. Wang, K. Nagai, T. Nakagawa, and A.W.-H. Mau. 1998. Effect of Polyethyleneglycol (PEG) on Gas Permeabilities and Selectivities in its Cellulose Acetate (CA) Blend Membranes. J. Membr. Sci. 138: 143-152.

[39] Bos, A., I. G. M. Punt, M. Wessling, and H. Strathmann. 1998. Plasticization-Resistant Glassy Polyimide Membranes for $\mathrm{CO}_{2} / \mathrm{CH}_{4}$ Separations. Sep. Purif. Tech. 14: 27-39.

[40] Staudt-Bickel, C. and W. J. Koros. 1999. Improvement of $\mathrm{CO}_{2} / \mathrm{CH}_{4}$ Separation Characteristics of Polyimides by Chemical Crosslinking. J. Membr. Sci. 155: 145-154.

[41] Shieh, J.-J. and T. S. Chung, 2000. Cellulose Nitrate-Based Multilayer Composite Membranes for Gas Separation. J. Membr. Sci. 166: 259-269.

[42] Hirayama, Y., T. Yoshinaga, Y. Kusuki, K. Ninomiya, T. Sakakibara, and T. Tamari. 1996. Relation of Gas Permeability with Structure of Aromatic Polyimide I. J. Membr. Sci. 111: 169-182.

[43] Suzuki, H., K. Tanaka, H. Kita, K. Okamoto, H. Hoshino, T. Yoshinaga, and Y. Kusuki. 1998. Preparation of Composite Hollow Fiber Membranes of Poly(ethylene oxide)-Containing Polyimide and Their $\mathrm{CO}_{2} / \mathrm{N}_{2}$ Separation Properties. J. Membr. Sci. 146: 31-37.

[44] Tokuda, Y., E. Fujisawa, N. Okabayashi, N. Matsumiya, K. Takagi, H. Mano, K. Haraya, and M. Sato. 1997. Development of Hollow Fiber Membranes for $\mathrm{CO}_{2}$ Separation. Energy Convers. Mgmt. 38: S111-S116.

[45] Wang, Z., T. Chen, and J. Xu. 2001. Gas and Water Vapor Transport through a Series of Novel Poly (aryl ether sulfone) Membranes. Macromolecules. 34: 9015-9022.

[46] Kim, J. H., S. Y. Ha, S. Y. Nam, J. W. Rhim, K. H. Baek, and Y. M. Lee. 2001. Selective Permeation of $\mathrm{CO}_{2}$ through Pore-Filled Polyacrylonitrile Membrane with Poly (Ethylene Glycol).J. Membr. Sci. 186: 97-107.

[47] Kapantaidakis, G. C., G. H. Koops, M. Wessling, S. P. Kaldis, and G. P. Sakellaropoulos. 2003. $\mathrm{CO}_{2}$ Plasticization of Polyethersulfone/Polyimide Gas-separation Membranes. AIChE. 49: 1702-1711.

[48] Liu, Y., T.-S. Chung, R. Wang, D. F. Li, and M. L. Chng. 2003. Chemical Cross-Linking Modification of Polyimide/Poly(ether sulfone) Dual-Layer Hollow-Fiber Membranes for Gas Separation. Ind. Eng. Chem. Res. 42: 1190-1195.

[49] - Mi, Y, X. Lu, and J. Zhou. 2003. Gas Diffusion in Glassy Polymers by a Chain Relaxation Approach. Macromolecules. 36: 6898-6902.

[50] Wind, J. D., C. Staudt-Bickel, D. R. Paul, and W. J. Koros. 2003. Solid-State Covalent CrossLinking of Polyimide Membranes for Carbon Dioxide Plasticization Reduction. Macromolecules. 36: 1882-1888.

[51] Robeson, L. M., C. D. Smith, and M. Langsam. 1997. A Group Contribution Approach to Predict Permeability and Selectivity of Aromatic Polymers. J. Membr. Sci. 132: 33-54.

[52] Alentiev, A. Y. and Y. P. Yampolskii. 2000. Free Volume Model and Tradeoff Relations of Gas Permeability and Selectivity in Glassy Polymers. J. Membr. Sci. 165: 201-216.

[53] Park, J. Y. and D. R. Paul. 1997. Correlation and Prediction of Gas Permeability in Glassy Polymer Membrane Materials via a Modified Free Volume Based Group Contribution Method. J. Membr. Sci. 125: 23-39. 
[54] Thran, A., G. Kroll, and F. Faupel. 1999. Correlation Between Fractional Free Volume and Diffusivity of Gas Molecules in Glassy Polymers. J. Poly. Sci. Part B: Polymer Physics. 37: $3344-3358$.

[55] Joly, C., S. Goizet, J. C. Schrotter, J. Sanchez, and M. Escoubes. 1997. Sol-Gel PolyimideSilica Composite Membrane: Gas Transport Properties. J. Membr. Sci. 130: 63-74.

[56] Joly, C., M. Samaihi, L. Porcar, and R. D. Noble. 1999. Polyimide-Silica Composite Materials: How Does Silica Influence Their Microstructure and Gas Permeation Properties. Chem. Mater. 11: 2331-2338.

[57] Kim, J. H. and Y. M. Lee. 2001. Gas Permeation Properties of Poly(Amide-6-b-Ethylene Oxide)Silica Hybrid Membranes. J. Membr. Sci. 193: 209-225.

[58] Smaihi, M., T. Jermoumi, J. Marignan, and R. D. Noble. 1996. Organic-Inorganic Gas Separation Membranes: Preparation and Characterization. J. Membr. Sci. 116: 211-220.

[59] Novak, B. M. 1993. Hybrid Nanocomposite Materials - Between Inorganic Glasses and Organic Polymers. Advanced Material. 5: 422-433.

[60] Cornelius, C. J. and E. Marand. 2002. Hybrid Silica-Polyimide Composite Membranes: Gas Transport Properties. J. Membr. Sci. 202: 97-118.

[61] Soufyani, M., T. Jei, D. Bourret, A. Sivade, and A. Larbot. 2001. Silicone Modified Silica Membrane. Application to the Gas Separation. Sep. Purif. Tech. 25: 451-457.

[62] Hu, Q., E. Marand, S. Dhingra, D. Fritsch, J. Wen, and G. Wilkes. 1997. Poly(Amide-Imide)/ $\mathrm{TiO}_{2}$ Nano-Composite Gas Separation Membranes: Fabrication and Characterization. J. Membr. Sci. 135: 65-79.

[63] Moaddeb, M. and W. J. Koros. 1997. Gas Transport Properties of Thin Polymeric Membranes in the Presence of Silicon Dioxide Particles. J. Membr. Sci. 125: 143-163.

[64] Koresh, J. E. and A. Sofer. 1983. Molecular Sieve Carbon Selective Membrane. Part I. Presentation of a New Device for Gas Mixture Separation. Sep. Sci. Tech. 18(8): 723-734.

[65] Fuertes, A. B. and T. A. Centeno. 1998. Preparation of Supported Asymmetric Carbon Molecular Sieve Membranes. J. Membr. Sci. 144: 105-111.

[66] Jones, C. W. and W. J. Koros. 1995. Characterization of Ultramicroporous Carbon Membranes with Humidified Feeds. Ind. Eng. Chem. Res. 34: 158.

[67] Kim, Y. K., K. H. Park, and Y. M. Lee. 2004. Carbon Molecular Sieve Membranes Derived from Thermally Labile Polymer Containing Blend Polymers and their Gas Separation Properties. J. Membr. Sci. 243: 9-17.

[68] Linkov, V. M., R. D. Sanderson, and E. P. Jacobs. 1994. Carbon Membranes from Precursors Containing Low-carbon Residual Polymers. Polymer International. 35: 239-242.

[69] Rao, M. B. and S. Sircar. 1996. Performance and Pore Characterization of Nanoporous Carbon Membranes for Gas Separation. J. Membr. Sci. 110: 109-118.

[70] - Sedigh, M. G., M. Jahangiri, P. K. T. Liu, M. Sahimi, and T. T. Tsotsis. 2000. Structural Characterization of Polyetherimide-based Carbon Molecular Sieve Membranes. AIChE. 46: 2245-2255.

[71] Strano, M. S. and H. C. Foley. 2001. Synthesis and Characterization of Catalytic Nanoporous Carbon Membranes. AIChE. 47: 66-78.

[72] Gilron, J, and A. Soffer. 2002. Knudsen Diffusion in Microporous Carbon Membranes with Molecular Sieving Character. J. Membr. Sci. 209: 339-352.

[73] Zhang, X., W. Zhu, H. Liu, and T. Wang. 2004. Novel Tubular Composite Carbon-zeolite Membranes. Materials Letters. 58: 2223-2226.

[74] Tin, P. S., T.-S. Chung, S. Kawi, and M. D. Guiver. 2004a. Novel Approaches to Fabricate Carbon Molecular Sieve Membranes Based on Chemical Modified and Solvent Treated Polyimides. Microporous and Mesoporous Materials. 73: 151-160. 
[75] Tin, P. S., T.-S. Chung, Y. Liu, and R. Wang. 2004b. Separation of $\mathrm{CO}_{2} / \mathrm{CH}_{4}$ through Carbon Molecular Sieve Membranes Derived from P84 Polyimide. Carbon. 42: 3123-3131.

[76] Park, H. B., S. Y. Lee, and Y. M. Lee. 2004. Pyrolytic Carbon Membranes Containing Silica: Morphological Approach on Gas Transport Behavior. J. Mol. Struc. In Press. Corrected Proof. Available online 26 November 2004.

[77] Shao, L., T.-S. Chung, G. Wensley, S. H. Goh, and K. P. Pramoda. 2004. Casting Solvent Effects on Morphologies, Gas Transport Properties of a Novel 6FDA/PMDA-TMMDA Copolyimide Membrane and its Derived Carbon Membranes. J. Membr. Sci. 244: 77-87.

[78] Barsema, J. N., S. D. Klijnstra, J. H. Balster, N. F. A. van der Vegt, G. H. Koops, and M. Wessling. 2004. Intermediate Polymer to Carbon Gas Separation Membranes Based on Matrimid PI. J. Membr. Sci. 238: 93-102.

[79] Lagorsse, S., A. Leite, F. D. Magalhāes, N. Bischofberger, J. Rathenow, and A. Mendes. 2005. Novel Carbon Molecular Sieve Honeycomb Membrane Module: Configuration and Membrane Characterization. Carbon. 43: 809-819.

[80] Zimmerman, C. M., A. Singh, and W. J. Koros. 1997. Tailoring Mixed Matrix Composite Membranes for Gas Separations. J. Membr. Sci. 137: 145-154.

[81] Jia, M., K.-V. Peinemann, and R.-D. Behling. 1991. Molecular Sieving Effects of Zeolite-Filled Silicone Rubber Membranes in Gas Permeation. J. Membr. Sci. 57: 289-296.

[82] Suer, M. G., N. Bac, and L. Yilmaz. 1994. Gas Permeation Characteristics of Polymer-Zeolite Mixed Matrix Membranes. J. Membr. Sci. 91: 77-86.

[83] Duval, J.-M., A. J. B. Kemperman, B. Folkers, M. H. V. Mulder, G. Desgrandchamps, and C. A. Smolders. 1994. Separation of Zeolite Filled Glassy Polymer Membranes. J. Appl. Poly. Sci. 54: 409-418.

[84] Gur, T. M. 1994. Selectivity of Zeolite Filled Polysulfone Gas Separation Membranes. J. Membr. Sci. 93: 283-289.

[85] Yong, H. H., H. C. Park, Y. S. Kang, J. Won, and W. N. Kim. 2001. Zeolite-Filled Polyimide Membrane Containing 2,4,6-Triaminopyrimidine. J. Membr. Sci. 188: 151-163.

[86] Gulsen, D., H. Hacarloglu, L. Toppare, and L. Yilmaz. 2001. Effect of Preparation Parameters on the Performance of Conductive Composite Gas Separation Membranes. J. Membr. Sci. 182: 29-39.

[87] Tantekin-Ersolmaz, S. B., C. Atalay-Oral, M. Tatier, A. Erdem-Senatalar, B. Schoeman, and J. Sterte. 2000. Effect of Zeolite Particle Size on the Performance of Polymer-Zeolite Mixed Matrix Membranes. J. Membr. Sci. 175: 285-288.

[88] Tantekin-Ersolmaz, S. B., L. Senorkyan, N. Kalaonra, M. Tatier, and A. Erdem-Senatalar. 2001. n-Pentane/i-pentane Separation by Using Zeolite-PDMS Mixed Matrix Membranes. J. Membr. Sci. 189: 59-67.

[89] - Pechar, T. W., M. Tsapatsis, E. Marand, and R. Davis. 2002. Preparation and Characterization of a Glassy Fluorinated Polyimide Zeolite-mixed Matrix Membrane. Desalination. 146: 3-9.

[90] Vu, D. Q., W. J. Koros, and S. J. Miller. 2003a. Mixed Matrix Membranes Using Carbon Molecular Sieves I. Preparation and Experimental Results. J. Membr. Sci. 211: 311-334.

[91] Vu, D. Q., W. J. Koros, and S. J. Miller. 2003b. Effect of Condensable Impurity in $\mathrm{CO}_{2} / \mathrm{CH}_{4}$ Gas Feeds on Performance of Mixed Matrix Membranes Using Carbon Molecular Sieves. J. Membr. Sci. 221: 233-239.

[92] Moore, T. T., T. Vo, R. Mahajan, S. Kulkarni, D. Hasse, and W. J. Koros. 2003. Effect of Humidified Feeds on Oxygen Permeability of Mixed Matrix Membranes. J. Appl. Poly. Sci. 90: $1574-1580$.

[93] Chung, T. S., S. S. Chan, R. Wang, Z. Lu, and C. He. 2003. Characterization of Permeability and Sorption in Matrimid/ $\mathrm{C}_{60}$ Mixed Matrix Membranes. J. Membr. Sci. 211: 91-99. 
[94] Hacarlioglu, P., L. Toppare, and L. Yilmaz. 2003. Polycarbonate-polypyrrole Mixed Matrix Gas Separation Membranes. J. Membr. Sci. 225: 51-62.

[95] Anson, M., J. Marchese, E. Garis, N. Ochoa, and C. Pagliero. 2004. ABS Copolymer-Activated Carbon Mixed Matrix Membranes for $\mathrm{CO}_{2} / \mathrm{CH}_{4}$ Separation. J. Membr. Sci. 243: 19-20.

[96] Jiang, L. Y., T. S. Chung, D. F. Li, C. Cao, and S. Kulprathipanja. 2004. Fabrication of Matrimid/ Polyethersulfone Dual-layer Hollow Fiber Membranes for Gas Separation. J. Membr. Sci. 240: 91.

[97] Jiang, L. Y., T.-S. Chung, C. Cao, Z. Huang, and S. Kulprathipanja. 2005. Fundamental Understanding of Nano-sized Zeolite Distribution in the Formation of the Mixed Matrix Single- and Dual-layer Asymmetric Hollow Fiber Membranes. J. Membr. Sci. In Press, Corrected Proof. Available online 13 January 2005.

[98] Koros, W. J. 1995. Membranes: Learning a Lesson from Nature. Chem. Eng. Prog. 68.

[99] Koros, W. J. and R. Mahajan. 2000. Pushing the Limits on Possibilities for Large Scale Gas Separation which Strategies? J. Membr. Sci. 175: 181.

[100] Kashiwagi, T., E. Grulke, J. Hilding, R. Harris, W. Awad, and J. Douglas. 2002. Thermal and Flammability Properties of Polypropylene/Carbon Nanotube Nanocomposites. Macromol. Rapid Commun. 23: 761-765.

[101] Poshusta, J. C., R. D. Noble, and J. L. Falconer. 2001. Characterization of SAPO-34 Membranes by Water Adsorption. J. Membr. Sci. 186: 25-40.

[102] Hasegawa,Y., K. Kusakabe, and S. Morooka. 2001. Effect of Temperature on the Gas Permeation Properties of NaY-type Zeolite Formed on the Inner Surface of a Porous Support Tube. Chem. Eng. Sci. 56: 4273-4281.

[103] Fang, J., H. Kita, and K.-I. Okamoto. 2001. Gas Permeation Properties of Hyperbranched Polyimide Membranes. J. Membr. Sci. 182: 254-256.

[104] Hirayama, Y., Y. Kase, N. Tanihara, Y. Sumiyama, Y. Kusuki, and K. Haraya. 1999. Permeation Properties to $\mathrm{CO}_{2}$ and $\mathrm{N}_{2}$ of Poly(ethylene oxide)-Containing and Crosslinked Polymer Films. J. Membr. Sci. 160: 87-99.

[105] Rezac, M. E., E. T. Sorensen, and H. W. Beckham. 1997. Transport Properties of Crosslinkable Polyimide Blends. J. Membr. Sci. 136: 249-259.

[106] Wright, C. T. and D. R. Paul. 1997. Feasibility of Thermal Crosslinking of Polyarylate GasSeparation Membranes Using Benzocyclobutene-Based Monomers. J. Membr. Sci. 129: 47-53.

[107] Wright, C. T. and D. R. Paul. 1997. Gas Sorption and Transport in UV-Irradiated Polyarylate Copolymers Based on Tetramethyl Bisphenol-A and Dihydroxybenzophenone. J. Membr. Sci. 124: 161-174.

[108] Wind, J. D., C. Staudt-Bickel, D. R. Paul, and W. J. Koros. 2002. The Effects of Crosslinking Chemistry on $\mathrm{CO}_{2}$ Plasticization of Poyimide Gas Separation Membranes. Ind. Eng. Chem. Res. 41: 6,139-6,148.

[109] Shieh, J.-J., T.-S. Chung, R. Wang, M. P. Srinivasan, and D. R. Paul. 2001. Gas Separation Performance of Poly(4-Vinylpyridine)/Polyetherimide Composite Hollow Fibers. J. Membr. Sci. 182: 111-123.

[110] Matsumoto, K., P. Xu, and T. Nishikimi. 1993. Gas Permeation of Aromatic Polyimides. I. Relationship between Gas Permeabilities and Dielectric Constants. J. Membr. Sci. 81: 15-22.

[111] Kuehne, D. L. and S. K. Friedlander. 1980. Selective Transport of Sulfur Dioxide through Polymer Membranes. Ind. Eng. Chem. Process Des. Dev. 19.

[112] Lehermeier, H. L., J. R. Dorgan, and J. D. Way. 2001. Gas Permeation Properties of Poly(Lactic Acid). J. Membr. Sci. 190: 243-251.

[113] Kim, J. H., S. Y. Ha, and Y. M. Lee. 2001. Gas Permeation of Poly(Amide-6-b-Ethylene Oxide) Copolymer. J. Membr. Sci. 190: 179-193. 